\title{
Synchrotron X-ray fluorescence imaging of strontium incorporated into the enamel and dentine of wild-shot orangutan canine teeth.
}

\author{
M. Christopher Dean ${ }^{1,2^{*}}$, Adeline Le Cabec ${ }^{3,4}$, Stijn J.M. Van Malderen ${ }^{5,6}$, Jan \\ Garrevoet $^{5}$
}

1Department of Earth Sciences, Centre for Human Evolution Research, Natural History Museum, Cromwell Road, London SW7 5BD, UK

${ }^{2}$ Department of Cell and Developmental Biology, University College London, Gower Street, London, WC1E 6BT, UK

${ }^{3}$ Department of Human Evolution, Max Planck Institute for Evolutionary

Anthropology, Deutscher Platz 6, D-04103 Leipzig, Germany

4PACEA, UMR 5199-CNRS, Université de Bordeaux, Bâtiment B8, Allée Geoffroy

Saint-Hilaire, CS 50023, 33615 Pessac Cedex, France

${ }^{5}$ Deutsches Elektronen-Synchrotron DESY, Notkestraße 85, 22607 Hamburg, Germany

${ }^{6}$ Department of Chemistry, Ghent University, Campus Sterre, Krijgslaan 281, 9000

Ghent, Belgium

Running title: Strontium distribution in orangutan canines

Declarations of Interest: none.

*Author for correspondence:

Christopher Dean

Email: ucgacrd@ucl.ac.uk

Orcid.org/0000-0003-3783-7296

\begin{abstract}
Objectives: Dental hard tissues contain trace elements of both dietary and environmental origin. One objective was to demonstrate that a longitudinal record of synchronous $\mathrm{Sr}$ incorporation into enamel and dentine can be retrieved from museum specimens of once-free-living endangered species. Further objectives were to quantify sudden fluctuations in $\mathrm{Sr}$ concentration and estimate the extent of $\mathrm{Sr}$ overprinting back into dentine and enamel formed prior to the time of $\mathrm{Sr}$ ingestion. Materials and Methods: Daily incremental markings were used to determine rates and times of tooth formation and synchrotron X-ray fluorescence of the same polished ground sections to image Sr distribution in a male and a female orangutan canine. The X-ray beam was monochromatised to $17.0 \mathrm{keV}$ and focused to $500 \times 500$ $\mathrm{nm}^{2}$. Scans were performed at either 25.0 or $5.0 \mu \mathrm{m}$ resolution.

Results: Baseline Sr levels ranged between 215-750 ppm. Multiple short, intense $\mathrm{Sr}$ labels reaching 750-1,625 ppm occurred randomly throughout 15-22 years of tooth formation. In dentine, Sr concentration increased gradually away from the EDJ, while in enamel, it reduced towards the enamel surface. Using daily incremental markings, Sr overprinting into earlier formed dentine and enamel was estimated to be $\sim 12-45$ days. There was no evidence of Sr overprinting by maturational ameloblasts. Conclusions: A good record of growth and trace element incorporation into tooth tissues can be retrieved from museum specimens. Short, intense Sr labels were
\end{abstract}


equally well time-resolved in enamel and dentine and could be distinguished from more diffuse background levels. Enamel maturation appears to have no quantifiable effect.

Keywords: Orangutan: SRXF: Strontium: Enamel: Dentine: Overprinting

\section{Highlights}

- Teeth of endangered species held in museums contain an archive of trace elements

- Maximal temporal resolution of Sr in teeth depends on an accessible growthrecord

- Higher background Sr levels in orang teeth than humans fit with a plant-based diet

- Sudden random peaks in Sr level/ingestion occurred throughout tooth formation

- Sr overprinting at peak levels ranged between 12-45 days in both dentine and enamel

\section{Introduction}

Many trace elements and stable isotopes are readily incorporated into dental hard tissues both before and after their formation. The alkaline earth metals $\mathrm{Sr}$ and $\mathrm{Ba}$ have a particular affinity for hydroxyapatite, where they may substitute for $\mathrm{Ca}$, but biologically they are non-essential trace elements. Their distribution and concentration in tooth tissues reflects background environmental levels and dietary intake but is also influenced by many physiological processes (Bentley, 2006). Other divalent trace metals, such as $\mathrm{Mg}, \mathrm{Cu}$ and $\mathrm{Zn}$, are involved in metabolic and developmental processes. In particular $\mathrm{Zn}$ is a component of many metalloproteinase enzymes involved in enamel maturation, which seems to account for its more diffuse distribution in surface enamel (Müller, Nava, Evans, Rossi, Alt \& Bondioli, 2019; Dean et al. 2019a). Many other trace elements continue to be taken up from the oral environment during life, such as fluoride or $\mathrm{Pb}$, and more so postmortem in an archaeological or palaeontological context from the burial environment where, for example, $\mathrm{Fe}, \mathrm{Mn}$ or $\mathrm{U}$ are readily incorporated into enamel, dentine and cementum. Because of its potential significance in reconstructing weaning, past diets, palaeodiets and geographic migration, Sr incorporation into tooth tissues has been the subject of intense scrutiny with doubts cast about the degree of chronological resolution that would ever be possible. The teeth available to us for this study allowed us to compare $\mathrm{Sr}$, $\mathrm{Ca}$ and $\mathrm{Zn}$ distribution in both enamel and dentine formed over many years and so to address a number of key issues about Sr incorporation and distribution. 
Dental hard tissues form appositionally over time and leave an incremental record of their growth. They also incorporate trace elements and stable isotopes into the organic and/or hydroxyapatite mineral phases in unique ways. Incremental markings are now used routinely to reconstruct a time scale for tooth growth and have proved an invaluable adjunct for studies in anthropology, archaeology and forensic science (Smith \& Tafforeau, 2008; Hillson, 2014; Witzel, 2014). Retrieving trace elements and stable isotopes from tooth tissues has also proved to be of enormous importance for reconstructing migration, diet, seasonality and periods of stress in the past (Balasse, Ambrose, Smith, \& Price, 2002; Balasse, Smith, Ambrose \& Leigh, 2003; Sponheimer, Passey, de Ruiter, Guatelli-Steinberg, Cerling \& Lee-Thorp, 2006; Sponheimer \& Cerling, 2014; Beaumont, Montgomery, Buckberry \& Jay, 2015; Austin et al. 2016; Green, Smith, Green, Bidlack, Tafforeau \& Colman, 2018; Joannes-Boyau et al. 2019). Every trace element and every stable isotope is likely to differ in the way it is incorporated into either enamel, dentine or cementum.

Nonetheless, general principles involved in establishing the degree of temporal resolution, and the challenges associated with this, come from considering the combined evidence for trace element and stable isotope incorporation into tooth tissues together. In reviewing this evidence, we identify a number of issues that can then be addressed, at least in part, by quantifying the distribution of Sr that has been simultaneously incorporated into enamel and dentine over a long period of time.

\subsection{The resolution of trace element sampling from tooth tissues}

Recent studies of trace elements have shifted away from the bulk sampling of enamel and dentine towards sampling techniques that can potentially provide greater spatiotemporal resolution within the tooth tissues, capable even of pinpointing specific events in the lives of individuals. With this has come increasing awareness that there is a potential mismatch between the increments of growth that are formed at the time ameloblasts and odontoblasts secrete organic matrix and the subsequent incorporation of mineral into each of the tooth tissues, that in the case of enamel, takes place over a long period of time (Sealy, Armstrong \& Schrire, 1995; Balasse, 2002; Kohn, 2002; Montgomery, Evans \& Horstwood, 2010; Montgomery, 2010).

A number of studies have attempted to document and/or model the degree of offset between the formation of incremental markings and the subsequent incorporation of mineral, trace elements and/or stable isotopes into enamel and dentine. Several studies have been made on thin-enamelled ungulate teeth where ladder-like sampling grooves have been cut into enamel along the length of the crown (Passey \& Cerling, 2001; Balasse, 2002; Balasse, Ambrose, Smith, \& Price, 2002; Balasse, Smith, Ambrose \& Leigh, 2003). Changes in stable $\delta^{13} \mathrm{C}$ isotope composition appeared as much as 6 to 7 months earlier in the chronological sampling series (Balasse, 2002) and in excess of 12 months earlier in the case of ${ }^{87} \mathrm{Sr} /{ }^{86} \mathrm{Sr}$ isotope ratios (Montgomery, Evans \& Horstwood, 2010) than known dietary changes in the experimental animals. A problem with this approach is that each sampling groove cuts through many complex incremental time-lines that run near parallel with the enamel surface, and so do not sample a tightly defined chronological zone. Similarly, serial transverse sections of root dentine certainly improve over bulk sampling techniques (Fuller et al. 2003; Beaumont, 2020) but also still cut across many incremental time-lines laid down over a considerable proportion of the root formation period in an often complex 3D manner, and, moreover, include secondary dentine 
formed close to the pulp chamber (Beaumont, Gledhill, Lee-Thorp \& Montgomery, 2013; Beaumont, Gledhill, \& Montgomery, 2014; Fahy et al. 2014; Sandberg, Sponheimer, Lee-Thorp \& Van Gerven, 2014). Tsutaya (2020) has demonstrated that even finely spaced $1 \mathrm{~mm}$ serial dentine sections encompass large time spans of tooth formation and result in misleading estimates of dietary change and age at weaning. As a result, these studies have provided, at best, only cautious optimism about the potential for achieving greater temporal resolution of trace elements and stable isotopes captured by mineralising enamel and dentine.

Greater success has come from sampling fractured or cut surfaces of teeth where the chronological sequence of incremental markings is more completely exposed. Crabb (1959) in human teeth and then Tafforeau, Bentaleb, Jaeger \& Martin (2007) in rhinoceros enamel, documented a region close to the enamel dentine junction (EDJ) which mineralises rapidly after matrix secretion and so may capture a higherresolution trace element and stable isotope profile than elsewhere in enamel. It has subsequently been shown that $\delta^{13} \mathrm{C}$ profiles measured close to the EDJ are near coincident with initial enamel secretion (Zazzo, Balasse \& Patterson, 2005). Whether this is because close to the EDJ $\delta^{13} \mathrm{C}$ escapes the greater effects of the enamel maturation process and whether this applies to all trace elements and stable isotopes equally is not clear. Nevertheless, studies of enamel further away from the EDJ using laser ablation inductively coupled plasma mass spectrometry (LA-ICPMS) that utilize small sampling areas of $\sim 25 \mu \mathrm{m}$ on polished ground sections of teeth have been equally encouraging. These studies have reported good correspondence between shifts in enamel chemistry across the neonatal line and known dietary changes occurring postnatally (Humphrey et al., 2004, 2007; Humphrey, Dean, Jeffries, \& Penn, 2008a; Humphrey, Dirks, Dean, \& Jeffries, 2008b; Humphrey, Jeffries \& Dean, 2008c). There also appears to be good correspondence between changes in normalised trace element profiles along the EDJ and those forming at the same chronological time along prism paths that extend through the full thickness of enamel towards the surface (Müller, Nava, Evans, Rossi, Alt \& Bondioli, 2019; Li, Nava, Reynard, Thirlwall, Bondioli \& Müller, 2020). Smith et al. (2018) have demonstrated that overprinting of Ba levels, that are elevated at birth, appear in sheep enamel with less than a month of minor elemental overprinting preceding the physical position of the neonatal line. In the light of this evidence Tacail et al. (2019) have also noted that the enamel maturation offset affecting $\mathrm{Ca}$ isotope composition is likely to be insignificant. Smith et al. (2018) have also presented data for $\delta^{18} \mathrm{O}$ values in sheep enamel that were first lowered and then increased again experimentally at known times, and that were also marked with a calcein labels in enamel. Corresponding changes in $\delta^{18} \mathrm{O}$ values were detected in enamel within a few days of the calcein labels marking these events. In particular, Smith et al. (2018) observed that lead exposure manifests almost synchronously in both enamel and dentine highlighting again that not all trace elements and/or stable isotopes are incorporated into tooth tissues in the same way and that the effects of enamel maturation may be much greater for some trace elements and stable isotopes than for others. Aware of this potential problem, Montgomery, Evans \& Horstwood (2010) have previously noted that a comparison of trace elements incorporated into dentine and enamel at the same time might further contribute to our understanding of any temporal mismatch between mineralisation and matrix secretion. Accordingly, in this study we have attempted to do this for Sr incorporation over a long period of time and to quantify any similarities and/or differences between enamel and dentine that 
might shed light on the processes at work during enamel and dentine secretion and enamel maturation.

\subsection{The time scale of mineral incorporation into enamel and dentine}

It is well established that the pattern of mineralisation in enamel and dentine differs (Irving, 1978). In forming dentine, complete mineralisation is almost immediate with no maturational phase (Bradford, 1958). Calcium is actively transported transcellularly from the pulp interstitial fluid to the extracellular dentine matrix. Significant levels of alkaline phosphatase and Ca-ATPase have been localised in the membrane vesicles and Golgi within the odontoblasts processes (Granstrom \& Linde, 1981; Bawden, 1989). $\mathrm{Ca}^{2+}$ ions bind to dentine phosphoprotein (DPP) and the hydroxyapatite crystallites that then form are seeded onto and within a matrix of collagen type I fibrils (Forien et al. 2015). Experiments have demonstrated that tritiated proline, $\left[{ }^{3} \mathrm{H}\right]$-proline, a key amino acid component of collagen, appears in predentine within 3 to 4 hours after injection and then subsequently in mineralised dentine 20 to 30 hours later, whereas labelled $\mathrm{Ca}$ ions appear in the odontoblast cell process between 30 minutes and 1 hour after entering the cell and less than 2 hours later in mineralised dentine (Irving, 1978; Schroeder, 1991).

Enamel mineralisation on the other hand occurs in phases over a long period of time. During the secretory phase enamel crystallites begin to form within 24 hours of enamel matrix secretion and while still only 0.05 to $0.1 \mu \mathrm{m}$ from the distal cell membrane of the ameloblast (Boyde, 1964, 1989; 1997; Irving, 1978; Schroeder, 1991). Enamel proteins pass from ribosomes, where they are manufactured, to secretory granules within 10 minutes and along with other components of the enamel matrix are present in forming enamel within 30 minutes (Sasaki, Takagi \& Yanagisawa, 1997). Autoradiograms have also shown that in thin-enamelled rat teeth, ${ }^{45} \mathrm{Ca}$ appears in enamel within 30 seconds of injection and has penetrated the whole thickness of developing enamel within 5 minutes (Hammarström, 1967; Leblond \& Warshawsky, 1984). Moreover, tetracycline antibiotics appear in the enamel matrix within 55 seconds of intra-cardiac administration, faster than they appear in dentine (Boyde, 1964). Thereafter, slow and controlled thickening of crystallites continues during the secretory stage that pack increasingly tightly together within in the deeper enamel and may even fuse together (Robinson et al. 1995; Robinson et al. 1997; Robinson, 2014; Hubbard, 2000; Al-Mosawi et al., 2018). Rosser, Boyde \& Stewart (1967) used scanning electron-probe X-ray emission microanalysis to quantify increasing $\mathrm{Ca}$ concentration in thick-enamelled human third molars. They calculated this to be linear with distance from the developing surface at $2.7 \%$ per $\mu \mathrm{m}$ and reaching over $90 \%$ in inner enamel prior to cessation of enamel matrix secretion at the enamel surface. At the end of the secretory stage, growth in enamel crystallite length ceases although Rosser, Boyde \& Stewart (1967) noted there is no second, sudden increase in mineral content at the start of a transitional or maturational stage. Robinson et al. (1995) and Simmons, Montgomery, Beaumont, Davis \& Al-Jawad (2013) have also emphasised that the precise timing of the various secretory and subsequent maturational phases of enamel formation, especially in thick-enamelled primate teeth, remains vague. Nonetheless, during the final maturation phase, $\mathrm{Ca}$ is actively transferred from the enamel surface inwards at the same time as degraded proteins are removed in a cyclic manner (Suga, 1989; Robinson et al. 1997; Smith, 1998; Hubbard 2000; 
Green et al. 2017). Large areas of surface enamel are covered by maturational ameloblasts and the pattern of mineralisation in this phase differs entirely from that during the secretory phase (Crabb, 1959).

\subsection{Trace element absorption and turnover}

Despite the apparently rapid transfer of mineral and other matrix components through odontoblasts and ameloblasts, there are other reasons to expect a blurring or lag in the temporal record of trace elements and stable isotopes retrieved from dental hard tissues. All elements, or chelating agents, with an affinity to bind or substitute with tooth tissues also do so with developing bone. For example, strontium or fluoride ingested and absorbed by the gastrointestinal tract are incorporated into forming bone and growing teeth at the same time. Plasma levels of. Rats given a single intraperitoneal injection of sodium fluoride had plasma levels that peaked 30 minutes later and then declined exponentially over 24-48 hours. However, fluoride was still detectable for at least 70 days, depending on the initial dose given, as ion exchange and/or bone remodelling released $\mathrm{F}^{-}$ions back into the circulation (Whitford, 1997). Bone turnover constantly releases a reservoir of stored $\mathrm{F}^{-}$and $\mathrm{Sr}^{+2}$, and other ions that have a long residency time, back into the circulation and it may take years for some to completely clear from the system (Kohn, 2004; Montgomery, Evans \& Horstwood, 2010). In a longitudinal study of growing dogs, fluoride retention in bone was shown to be a direct function of age and took $\sim 4$ years to decline to $\sim 50 \%$ (Whitford, 1997) and there is evidence tetracycline laid down in human bone may persist for more than 9 years (Ibsen \& Urist, 1964). It seems likely that Sr, with a similar affinity for bone, would also be retained in the skeleton and slowly released over a similarly long period of time. The implication of this is that $\mathrm{Sr}$ incorporated into enamel and dentine close to the time of mineralisation does not then necessarily only comprise $\mathrm{Sr}$ ingested and absorbed by the gastrointestinal tract but also includes $\mathrm{Sr}$ released from skeletal stores. An important question is whether a sudden higher than usual dose of $\mathrm{Sr}$ ingested and absorbed via the gastrointestinal tract may overwhelm this circulating background reservoir and, for a period of time, form a greater proportion of the Sr incorporated into enamel and dentine.

When a high loading dose of $\mathrm{Sr}$ is administered, $\mathrm{Sr}$ is preferentially laid down and stored in faster forming trabecular bone than in cortical bone (Dahl et al. 2001). Under these circumstances, only a small proportion of $\mathrm{Sr}^{2+}$ ions substitute directly for $\mathrm{Ca}^{2+}$ ions within the apatite lattice - one atom in 10 has been suggested (Rokita, Hermes, Nolting, Ryczek, 1993; Dahl et al. 2001; Shepherd et al. 2012). It has been proposed that the majority are incorporated by ion exchange onto the apatite crystal surface (Whitford, 1997; Dahl et al. 2001). Prolonged high Sr intake quickly saturates the crystal surface and limits further Sr uptake. As a result Sr uptake levels off with no further increase. However, the endosteal surface of trabecular bone is physiologically dynamic and constantly involved in Ca homeostasis. Immediately after dose withdrawal, Sr clears from the apatite crystal surfaces in trabecular bone, maintaining high circulating levels. This is quickly excreted by the kidneys that favour Ca reabsorption over Sr (Dahl et al. 2001). Under these circumstances, with a high Sr intake and the potential for it to clear comparatively quickly from the skeletal reservoir, Sr may be incorporated into enamel and dentine more sharply and completely and within a relatively short timescale that better reflects $\mathrm{Sr}$ ingested and absorbed from the gastrointestinal tract at the time of mineralisation (Humphrey, 
Dean, Jeffries, \& Penn, 2008a; Humphrey, Dirks, Dean, \& Jeffries, 2008b; Humphrey, Jeffries \& Dean, 2008c; Shepherd et al. 2012; Müller, Nava, Evans, Rossi, Alt \& Bondioli, 2019). A precise model of the time scale for Sr incorporation into enamel following a higher than usual dose, and how this compares with synchronously formed dentine, is yet to be established.

\subsection{Aims of the study}

Rare museum specimens may contain an archive of information embedded within their tooth tissues and thus may be able to play a key role in resolving questions about the long-term incorporation of trace elements into enamel and dentine. One aim of this study was to use daily incremental markings in enamel and dentine to reconstruct a longitudinal record of permanent orangutan canine tooth growth from a wild-shot male and a female. A second aim was to use synchrotron X-ray fluorescence (SXRF) imaging to superimpose a temporal record of Sr incorporation in dentine onto this record of growth in tooth length. Specifically, we aimed to quantify any cumulative increase in baseline/background $\mathrm{Sr}$ concentration during the growth of these teeth (and of the individual) as well as map the distribution of any sudden, short, intense peaks in Sr concentration that were greater than adjacent background levels. For a smaller region of interest in the female canine, our aims were to compare the distribution and concentration of Sr incorporated simultaneously into enamel and dentine and to identify any gradients in Sr concentration common to both. A further specific aim was to use daily incremental markings to estimate the extent to which Sr spreads back into (or over-prints) enamel and dentine formed prior to the time secretory ameloblasts and odontoblasts were first exposed to higher than usual levels of Sr. A final aim was to compare the distribution of $\mathrm{Zn}$ and $\mathrm{Sr}$ in enamel and dentine and to identify any differences that might result directly from the extended maturational phase of enamel formation.

\section{Materials}

Smith et al. (2017) and Smith (2016) have previously noted that primate dentitions, and especially those of critically endangered species, collected in the past and now curated in museum collections, are an important archive for histological and trace element studies today. The Elliot Smith Collection at University College London contains over 140 primate specimens including more than 50 wild shot and captive great ape specimens. Of these 17 are catalogued as Pongo pygmaeus and include three mature adult males, four mature adult females as well as 10 infant or juvenile specimens. Nine of the 17 Pongo pygmaeus specimens were more than likely acquired as a single batch and each have the accession number CA28. Eight of these have an additional suffix -JS2 through -JS8. One, (CA28-JS4) is also marked 18.1.23 that may be a date suggesting these individuals were collected approximately 100 years ago and the first catalogued specimens were indeed published soon after this (Zuckerman, 1928). Longitudinal ground sections of an adult male orangutan permanent left lower canine (accession number CA28) and an adult female orangutan permanent right upper canine (accession number CA28-JS3) have previously been used in studies of comparative dental development (Schwartz \& Dean, 2001; Schwartz et al. 2001; Dean, 2010; Dean et al. 2018). Evidence for these individuals having originally lived in their natural habitat and being wild shot comes from retained black supragingival staining of the teeth, advanced dental 
attrition and the effects of chronic periodontal disease (Dean et al. 1992) as well as direct evidence of bullet and/or cut-mark damage (Fig. 1).

\section{Methods}

\subsection{Histology methods - specimen preparation}

Two permanent orangutan canines, one from a female and one from a male, were sectioned longitudinally with a low speed diamond saw (Buehler IsoMet). Two serial longitudinal ground sections of the female orangutan permanent upper canine (CA28-JS3) were prepared as follows. Following an initial cut through the female canine, both block faces were polished using a graded series of abrasive papers and finished with $3 \mu \mathrm{m}$ aluminium polishing powder and deionised water on a polishing pad. Both polished surfaces of each tooth were cleaned in an ultrasonic bath, dried and then fixed to $1 \mathrm{~mm}$ thick glass slides with zero-bond epoxy resin (Huntsman Araldite 2020) under pressure for 48 hours. A further cut was then made through each tooth block parallel with the glass slide leaving a 300-400 $\mu \mathrm{m}$ thick longitudinal section of the tooth attached to each of the slides. These were then ground and lapped to between 80-100 $\mu \mathrm{m}$ and polished. No coverslips were placed leaving the polished surfaces exposed for synchrotron X-ray fluorescence scanning (SRXF). After polishing, all sections were cleaned ultrasonically in deionised water, but no etching or surface treatment of any kind was carried out. One of the female canine sections was then removed from the glass slide by soaking it in dimethylformamide for 2 days until the section easily slid off. This section was then dehydrated through a graded series of alcohol baths before mounting onto Kapton polyimide film. The male canine sections and the second female canine section which each showed evidence of extensive shrinkage cracks were considered too fragile to be removed from the glass slide and so were scanned as originally mounted.

A single longitudinal ground section of the male canine (CA28), had originally been prepared for a previous study (Schwartz et al., 2001). However, this section only captures the cuspal third of the enamel well and passes obliquely through the cervical enamel and includes no root dentine. For the purposes of this study, therefore, an additional ground section of the male canine was prepared that passed both through the enamel and the long axis of the root. To do this, the original tooth blocks were re-apposed in their correct anatomical relation with a sticky-wax separator. This second longitudinal section of the male canine was then cut through both blocks to include the whole length of the root and finished as described above for the female canine section. No attempt was made to include the lowest point on the enamel cervix as estimating crown formation time was not an objective of this study. As a result, this second longitudinal ground section of the male canine is missing a portion of the crown caused partly by the previous saw cut but also by damage to the thin and unsupported buccal enamel and dentine in this region. This missing portion of the enamel is visible in the figures and data plots but growth in tooth length could be reconstructed using both ground sections.

\subsection{Histology methods - data collection}

Digital micrographs were recorded using a Canon EOS 6D camera body mounted onto a Zeiss Jenamed II microscope. Transmitted light micrographs were recorded 
both in polarised and non-polarised light using a range of objective lenses (2.5x, $6.3 x, x 12.5 x, 25 x, 50 x)$. The methods used to calculate enamel formation time and root formation time in this study have previously been described and illustrated in detail (Dean, 2012a; Guatelli Steinberg, Floyd, Dean \& Reid, 2012; Dean \& Cole, 2013; Dean, Humphrey, Groom \& Hassett, 2020) but are briefly outlined again here. Regions of inner enamel within $200 \mu \mathrm{m}$ of the enamel dentine junction (EDJ) were identified that showed clear daily enamel cross striations. Repeated measurements were made in each region across groups of 6 cross striations (representing 5 days enamel secretion) and an average cross striation spacing, or repeat interval, equivalent to the linear daily enamel secretion rate, was calculated for each region. The time taken to form a $200 \mu \mathrm{m}$ thickness of inner enamel was then calculated using this average daily rate. Repeated $200 \mu \mathrm{m}$ lengths along prism paths were then measured from the EDJ into the enamel in the direction of the enamel surface. From each end-point of the $200 \mu \mathrm{m}$ measurement within the enamel, a line was then tracked back to intersect with the EDJ along, or parallel with, a stria of Retzius. Starting in the cusp, this procedure was repeated along the EDJ to the enamel cervix and the sum of all the $200 \mu \mathrm{m}$ prism paths required to reach the cervix recorded. Total enamel formation time equals the time taken to form a single $200 \mu \mathrm{m}$ prism length multiplied by the total number of prism lengths contained within the crown. The cumulative length along the EDJ and cumulative time taken to form the enamel preserved was then calculated.

Following the methods described in Dean \& Cole (2013), regions in the root dentine within $200 \mu \mathrm{m}$ of the cementum dentine junction (CDJ) were identified where daily increments of dentine could be visualised. Repeated measurements were made in each region across groups of 6 daily dentine increments (representing 5 days of dentine mineralisation) and an average daily rate calculated for each region. In the same way as in enamel, a $200 \mu \mathrm{m}$ length was extended from the CDJ into dentine in the direction of the pulp - but this time along dentine tubules, representing the direction of dentine matrix secretion. From this end point within dentine, a line was tracked back to the CDJ, parallel with the incremental (i.e. with an Andresen line or regular long-period marking) or other accentuated marking aligned along the former developing front in root dentine. The same procedure was then repeated until the root apex was reached. Total root dentine formation time equals the time taken to form each $200 \mu \mathrm{m}$ length along dentine tubules multiplied by the total number of such lengths measured along the root. The total cumulative length, or cumulative formation time, along the EDJ and CDJ from the first preserved enamel to the root apex was plotted against Sr concentration.

\subsection{Synchrotron methods - data collection}

Experiments were performed on the P06 Beamline (Schroer et al. 2010; Boesenberg et al., 2016), Petra III, at DESY (Deutsches Elektronen-Synchrotron, Hamburg, Germany). The storage ring was operated in 40-bunch mode using top-up filling mode with a current of $100 \mathrm{~mA} \pm 0.5 \mathrm{~mA}$. The primary X-ray beam was monochromatised to $17.0 \mathrm{keV}$ using a double crystal Si111 monochromator and focused using a Kirkpatrick-Baez (KB) mirror system (JTEC, Japan) to $500 \times 500$ $\mathrm{nm}^{2}$. For this experiment, the set-up comprises a Maia 384C detector system (Kirkham et al., 2010), ideally used in "backscatter" geometry to maximise the solid angle during analysis of thin polished samples ( 100 $\mu \mathrm{m}$-thick in this study), and 
allowing for large area SXRF imaging with a sub- $\mu$ m resolution using millisecond dwell times (Falkenberg et al. 2017). Further details on the set-up are provided in Dean et al. $(2018,2019)$. Elements of primary interest were Ca, Sr, and Zn. Spectral analysis, deconvolution and initial image analysis of the fluorescence data were performed using GeoPIXE 7.4f. The X-ray yield calculations were performed assuming a hydroxyapatite matrix $\left(\mathrm{Ca}_{10}\left(\mathrm{PO}_{4}\right)_{6}(\mathrm{OH})_{2}\right)$ with density $3.1 \mathrm{~g} / \mathrm{cm}^{3}$ close to enamel (Weidmann et al., 1967) and final sample thickness of 80-100 $\mu \mathrm{m}$. Glass slides or Kapton polyimide film substrates were included in the overall sample model as appropriate. Concentrations were determined using a conversion factor (photon counts to equivalent charge) through measurement of a standard $\mathrm{Ni}$ foil with areal density $50.0 \mathrm{\mu g} / \mathrm{cm}^{2}$ (Micromatter Technologies Inc. Canada). Elemental distribution maps were normalised to the incoming X-ray flux. SXRF concentrations are reported as parts-per-million (ppm or $\mu \mathrm{m} / \mathrm{g}$ ).

Lower resolution overview scans of each entire histological section were first acquired. The female orangutan canine overview (CA28-JS3) was made at $25 \mu \mathrm{m}$ resolution with $10 \mathrm{~ms}$ dwell time and took 3 hours. The male canine overview (CA28) was made at $25 \mu \mathrm{m}$ resolution with $10 \mathrm{~ms}$ dwell time and took 4.2 hours. A higher resolution scan of a specific region of interest in the crown of the same female orangutan canine section was made at $5 \mu \mathrm{m}$ resolution $(10 \mathrm{~ms}, 0.5 \mathrm{~h})$. A further SRXF scan was made on the second longitudinal ground section of the female orangutan canine (CA28-JS3) with a different detector configuration consisting of two collimated Vortex EM silicon drift detectors, Hitachi High-Tech Science America, Inc., positioned symmetrically at back-scattering angles of 135 degrees at a distance of 9 $\mathrm{mm}$ from the focal points, and scanned at $5 \mu \mathrm{m}$ resolution $(10 \mathrm{~ms}, 0.5 \mathrm{~h})$. This scan included a greater area of enamel and dentine than the first higher resolution scan and was made during a subsequent measurement session.

\subsection{Synchrotron methods - data analysis}

Two sets of profiles of either $\mathrm{Sr}$ alone, or of $\mathrm{Sr}$ and $\mathrm{Zn}$ together, were made along transects defined on the SXRF scans. First, on the overview scans $(25 \mu \mathrm{m})$ of both the male and female canines, and using GeoPIXE 7.4f, a curved transect was traced along the whole length of the tooth from the first preserved enamel to the root apex. This transect was traced in dentine throughout, first close to the EDJ in the crown and then onwards in the root close to the CDJ (Fig. 2a). The length of this curved transect was checked against the total tooth length calculated separately from digital montages to ensure they matched. Profile plots of Sr intensity (concentration in ppm) in dentine along these transects of tooth length were made against increasing tooth length for both the male and female orangutan canine teeth. In each plot alternating odd and even yearly increments of time were depicted as dark and light symbol infills.

Second, a specific region of interest was defined in the female canine crown on a higher resolution image $(5 \mu \mathrm{m})$ where 5 or 6 intense matching Sr labels in enamel and dentine were imaged intersecting the EDJ (red box in Fig. 2a). Further transects across the enamel and dentine in this region were defined to generate profiles of trace element intensity (concentration) and to quantify $\mathrm{Sr}$ and $\mathrm{Zn}$ gradients relative to distance from the EDJ. These transects were made in several planes that are reported and illustrated in the results section. Where these were for lengths that 
directly followed prism paths and dentine tubules, a timescale was calculated using measurements and counts of daily enamel increments made within the particular field of view of each plot.

\section{Results}

\subsection{Female Pongo canine (CA28-JS3) - enamel histology}

High power micrographs taken at the EDJ with 25x and 50x objective lenses imaged clear cross striations in several regions (Fig. 3). At 6 or 7 positions along the EDJ, and along prism paths within $200 \mu \mathrm{m}$ of the EDJ, measurements were made across 6 cross striations and divided by 5 days (mean $3.97 \mu \mathrm{m}$; range 3.25-4.24; SD 0.26). The average time taken to form a $200 \mu \mathrm{m}$-long prism segment was then calculated to be $200 / 3.97=51$ days. These measurements of cross striation spacings indicate that the extension rate and the daily enamel formation rate are constant close to the EDJ over this period of enamel formation, as also evidenced by near-parallel and equally spaced striae that only begin to diverge towards the enamel surface.

The preserved enamel in this ground section contained a total of thirty-one $200 \mu \mathrm{m}$ long prism segments. Hence the total preserved enamel formation time is equal to $31 \times 51=1581$ days/365 or 4.35 years. However, some cuspal enamel is lost through wear and the lowest part of the enamel cervix is not contained in this ground section. The second ground section of this tooth preserves $43 \times 51=2193$ days, or 6 years, of enamel formation but this is at the expense of root contained in the first section. Even though this second section could not be used for root formation, or to estimate a total tooth formation time, it does suggest total enamel formation time would still have been within the range reported by Schwartz and Dean (2001) for female orangutan canines ( $5.47 \pm 0.73$ years). This second section was, however, used to image regions of interest in enamel alongside the first section.

\subsection{Female Pongo canine (CA28-JS3) - dentine histology}

The mean spacing of daily dentine increments (Fig. 3), representing the rate of formation, was calculated in 14 different positions from the cementum dentine junction (CDJ) between zero to $100 \mu \mathrm{m}$ (mean $2.24 \mu \mathrm{m}$; range 0.77 to $2.96 \mu \mathrm{m}$; SD $0.64 \mu \mathrm{m})$, and again in 14 different positions between 100 and $200 \mu \mathrm{m}$ from the CDJ (mean $2.81 \mu \mathrm{m}$; range 2.22 to $3.52 \mu \mathrm{m}$; SD $0.39 \mu \mathrm{m}$ ). The overall average spacing, or daily dentine formation rate, across the whole $200 \mu \mathrm{m}$ thickness of root dentine was $2.52 \mu \mathrm{m} /$ day, which was rounded to $2.5 \mu \mathrm{m} /$ day. These data are comparable with those from other studies that include great ape root dentine (Dean, 2012b). Notably, the mean rate recorded for a gorilla canine within the first formed $100 \mu \mathrm{m}$ was $2.2 \mu \mathrm{m} /$ day but this formed at a faster rate between 100 to $200 \mu \mathrm{m}$ (3.25 $\mu \mathrm{m} /$ day). Each $200 \mu \mathrm{m}$ segment was calculated to take 80 days (200/2.5=80 days). Along the whole root length, from the last enamel preserved at the cervix, down to the root apex, there were 52 segments, each measured along dentine tubules. This equals $52 \times 80=4,160$ days or 11.39 years. When added to the time taken to form enamel preserved in this ground section the total preserved tooth formation time is $4.35+11.39=15.74$ years. However, as previously noted, as much as 18 months of enamel formation may have been lost in this specimen. 
Having established the basis of a time scale for crown and root formation in this female orangutan canine a transect, indicated by the dotted line in Figure $2 \mathbf{a}$, was defined within the dentine along the length of the preserved EDJ and CDJ. The SXRF map of this whole tooth section shows the path of the dentine transect along which Sr concentration in the ground section was plotted against increasing tooth length $(\mu \mathrm{m})$. Alternate odd and even years of tooth formation were then superimposed onto this plot with either light or dark symbols (Fig. 2b). From general background levels of Sr concentration in dentine of between 200 and 400 ppm, there are sudden peaks in Sr concentration along the whole tooth length that reach between $\sim 500$ and 700 ppm with one in excess of 1,700 ppm.

\subsection{Male Pongo canine (CA28) - enamel and dentine histology}

The results derived from the male orangutan ground sections were collected in the same way as those for the female ground section. At three positions along the EDJ within $200 \mu \mathrm{m}$ of the EDJ, the mean of measurements across 6 cross striations, divided by 5 days, were respectively 3.6, 3.3 and $4.0 \mu \mathrm{m}$ (grand mean $3.64 \mu \mathrm{m}$ ). The average time taken to form $200 \mu \mathrm{m}$ along a prism path was then calculated to be $200 / 3.64=54.9$, which was rounded to 55 days. As describe above, one of the two available ground sections of the crown has a portion of enamel missing (Fig. 4a) caused by a previous saw cut and by damage to the specimen. Sixteen $200 \mu \mathrm{m}$-long prism segments in the first section were extended out from the EDJ cuspally and then projected back to the EDJ along, or parallel with, an incremental stria to a clear feature just distal to the saw cut and visible in both ground sections. From this shared feature in the second section, 30 further prism segments were traced and tracked back to the EDJ in sequence until the enamel cervix was reached. The sum of $200 \mu \mathrm{m}$ prism lengths preserved in the enamel totalled 46 , which is equal to $46 \times 55=2,530$ days or 6.93 years.

Too few clear daily dentine increments were visible in this male canine to provide a reliable representation of formation rates across the first-formed $200 \mu \mathrm{m}$ at the CDJ. For this reason, the same data for daily dentine rates collected in the female orangutan canine were used to calculate the root formation time. There were 69 root segments of 80 days each equal to $80 \times 69=5,520$ days or 15.12 years. It follows the total preserved tooth formation time was $15.12+6.93=22.05$ years.

Figure 4a shows the overview SXRF map of Sr concentration in the ground section of the male orangutan canine and the transect, represented by the dotted line, defined using GeoPIXE 7.4f. Sr concentration in dentine, close to the EDJ and CDJ, is plotted against increasing tooth length (Fig. 4b). General background levels of $\mathrm{Sr}$ concentration in dentine increase gradually from 150 to $250 \mathrm{ppm}$. As in the female canine, there are sudden irregular peaks in Sr concentration that reach $\sim 300$ to 500 $\mathrm{ppm}$ along the whole tooth length. The break in $\mathrm{Sr}$ data that fall to zero at $\sim 5,000 \mu \mathrm{m}$ of tooth length corresponds with damage to the crown and ground section. Figure 5 shows the normalised $\mathrm{Sr} / \mathrm{Ca}$ data for both female and male canines plotted together. The missing data for the male canine between $\sim 5,000$ and $7,500 \mu \mathrm{m}$ of tooth length were omitted from Figure 5. This demonstrates the degree to which differences in $\mathrm{Sr}$ concentration between the male and female canine are proportionate to changes in Ca concentration. 


\subsection{Higher resolution region of interest - female Pongo canine (CA28-JS3)}

One particular region of interest (indicated by the red box in Figure 2) in the crown of this female orangutan canine was chosen for further study because 5 or 6 prominent Sr labels in enamel each have a very clear matching label in the dentine. These matching lines are shown at higher resolution in Figure 6 . There are, however, also other faint labels visible in enamel that do not appear to have visible matching bands in dentine. Seven $200 \mu \mathrm{m}$-long prism segments encompass the EDJ from the first to the last $\mathrm{Sr}$ label in this region of interest, each representing 51 days and so totalling 357 days of enamel and dentine formation. Therefore, this region of interest represents approximately 1 year of enamel and dentine formation along the EDJ.

In the higher SXRF maps $(5 \mu \mathrm{m})$ of enamel and dentine from the mid-crown of this ground section, the spacing between the matching Sr labels show that rates of enamel formation were much greater than rates of dentine formation close to the EDJ (Fig. 6). Individual increments of dentine formation were not visible here but rates were calculated from the proportionate spacing of the matching Sr labels common to both enamel and dentine. The proportion of dentine tubule length to total inner enamel prism length between matching Sr label peaks was measured 5 times close to the EDJ and averaged $26.8 \%$ (range 25.2 to $29.6 \%$ ). It follows $26.8 \%$ of the enamel formation rate, which is $3.9 \mu \mathrm{m} /$ day, indicates a dentine formation rate of $1.05 \mu \mathrm{m} /$ day close to the EDJ, which corresponds with the lowest rates (0.77-1.26 $\mu \mathrm{m} /$ day) measured close to the CDJ in root dentine. However, as in root dentine, there is a gradient across the series of $\mathrm{Sr}$ labels in coronal dentine so that rates close to the EDJ are slower than those further away. Along dentine transect $A$ in Figure 6 , dentine rates rose from $26.8 \%$ to $40 \%$ between the two last-formed $\mathrm{Sr}$ lines peaks $(0.4 \times 3.9 \mu \mathrm{m} /$ day $=1.56 \mu \mathrm{m} /$ day $)$.

Figure 6 shows the higher resolution SXRF map ( $5 \mu \mathrm{m}, 10 \mathrm{~ms}, 0.5 \mathrm{~h})$ of this region of interest showing matching $\mathrm{Sr}$ labels in enamel and dentine. Transects across the dentine $(A)$ and across two regions of the enamel ( $B$ and $C$ ), each made perpendicular to the forming mineral fronts, are indicated on the map (green bars) alongside the accompanying SXRF Sr concentration plots. Matching $\mathrm{Sr}$ concentration peaks in enamel and dentine are numbered 1 to 6 . In one case a small peak (Sr peak 2) in enamel concentration has no clear match in dentine so close to the EDJ. Strontium labels in enamel and dentine are plotted here against formation time from the origins of transects $A$ and $B$ at the EDJ. Time (days) is derived from the estimates of daily enamel and dentine formation rates made in this region.

Enamel line 5 in transect $C$ is not plotted from the EDJ but is cross-matched with enamel line 5 in transect $B$ and plotted in continuity with it through time. In the plot, the vertical line at zero represents the EDJ and the direction of dentine formation is from zero to 600 days into dentine. Enamel formation is from zero into positive values of enamel thickness for 600 days. The range of variation in peak $\mathrm{Sr}$ concentration is generally greater in enamel than in dentine. In both enamel and dentine $\mathrm{Sr}$ concentration within each of the labels appears to rise and fall nearsymmetrically either side a peak value. The peak values in dentine range from 430 to $660 \mathrm{ppm}$ above an adjacent baseline value of $\sim 300 \mathrm{ppm}$. In enamel peak values ranged between 630 to $1,625 \mathrm{ppm}$ above adjacent baseline values (between 450 and $750 \mathrm{ppm}$ ). Strontium concentration in enamel is generally higher towards the EDJ than close to the enamel surface, although this may be influenced by higher 
doses of $\mathrm{Sr}$ in some label lines than others. This is not the case in dentine where the baseline level remains almost constant at $\sim 300$ ppm. Figure 7 shows $\mathrm{Sr} / \mathrm{Ca}$ for the same enamel and dentine transects shown in Figure 6 once again plotted together against formation time. Towards the enamel surface these are closely superimposed but towards the EDJ Sr/Ca values are higher in enamel than dentine. The inset in Figure 7 illustrates how for enamel line 1 in transect $C$, by way of example, the peak concentration value ' $p$ ' occurred $210 \mu \mathrm{m}$ from the EDJ with the start of the rise in values $140 \mu \mathrm{m}$ closer to the EDJ ('a' in the inset) and then how the subsequent return to background level occurred $65 \mu \mathrm{m}$ beyond the peak value ('b' in the inset).

Figure $\mathbf{8}$ is of the same region of interest in the female orangutan canine as illustrated in Figures 2 and 6 . It shows transects along the peak values within $\mathrm{Sr}$ labels in enamel and dentine where the Sr concentration is highest. The transect in enamel (E1) is superimposed directly along a former mineralising front extending between the EDJ and the enamel surface. The transect in dentine (D2) is superimposed along the matching mineralising front and $\mathrm{Sr}$ label that was laid down at the same time as that in enamel. The plots show profiles for both $\mathrm{Sr}$ and $\mathrm{Zn}$ along these transects. In enamel (E1) there is a gradient in Sr concentration that falls from $\sim 1,500 \mathrm{ppm}$ close to the EDJ to $\sim 500 \mathrm{ppm}$ at the enamel surface. In dentine (D2) there is also a gradient but this is more gradual and variable as Sr concentration increases away from the EDJ from $\sim 450 \mathrm{ppm}$ to $\sim 650 \mathrm{ppm}$. Zinc concentration is also plotted here and remains constant at $\sim 100 \mathrm{ppm}$ in dentine (D2) but the pattern in enamel (E1) is different and rises steeply from near zero in inner enamel to $\sim 2,000$ ppm at the enamel surface.

Figure 9 shows two further transects again in the same region of interest in the female orangutan canine. In enamel (E3) and dentine (D3), are transects along two mineralising fronts formed earlier than in Figure 8 but this time along two regions with the lowest $\mathrm{Sr}$ concentrations between $\mathrm{Sr}$ label lines. They represent baseline levels between peaks in Sr levels. The same gradients in $\mathrm{Sr}$ concentration exist but are now much less pronounced. In enamel (E3) Sr levels fall from $\sim 700$ ppm close to the EDJ to $\sim 400 \mathrm{ppm}$ at the enamel surface. In dentine (D3) they rise from the EDJ into deeper formed dentine but only by 50 ppm (from $\sim 250$ to $\sim 300$ ppm). Again, Zn concentrations rise from near-zero in the inner enamel to very high levels, $\sim 1,500$ ppm in this transect, at the enamel surface. Zinc levels in dentine (D3), as in the previous plot (Fig. 8), are near-constant at $\sim 100$ ppm. Strontium gradients in both dentine and enamel are greatest along the transects that represent mineralising fronts with the highest Sr concentrations (see Figure 8). Zn concentrations follow a quite different pattern and appear to be independent of changes in Sr concentration.

\subsection{Baseline levels of Sr in the male and female canines}

Using Figures 2 and 4, regions of the male and female orangutan canines were identified that appeared to show the lowest concentrations of Sr. In enamel, the lowest value in the female canine was 437 ppm (range 424 to 450 ppm) and in the male 277 ppm (range 267 to 292 ppm). In dentine, the lowest value in the female canine was 224 ppm (range 215 to $251 \mathrm{ppm}$ ) and in the male $168 \mathrm{ppm}$ (range 145 to 182 ppm). The minimum background levels were consistently different between the male and female teeth with higher values in the female in both enamel and dentine. As already noted in the male canine, there appears to be a cumulative rise in the 
background $\mathrm{Sr}$ concentration throughout tooth formation that is directly related to changing $\mathrm{Ca}$ concentration (Figure 5) but both $\mathrm{Ca}$ and $\mathrm{Sr}$ concentration remain near-constant in the female canine.

\subsection{The temporal incorporation of strontium into forming enamel and dentine}

Within the region of interest in the female orangutan canine ground section, six peaks in Sr concentration in enamel (Figs. 6,7) were matched with 5 peaks formed at the same time in dentine and were numbered 1 to 6 in order of their formation (Figure 6, Table 1). As noted, one minor peak in enamel ( $\mathrm{Sr}$ line 2) has no matching peak along the dentine transect close to the EDJ and only appears further into dentine formation where rates of secretion are faster. The data in Table 1 are derived from the scan settings as processed by GeoPIXE 7.4f. Strontium concentrations were measured at $5 \mu \mathrm{m}$ intervals. The distance of each peak in $\mathrm{Sr}$ concentration from the EDJ as it crossed each transect is proportionate to its time of formation (Peak in Table 1 and ' $p$ ' in Fig 7 inset). The distance $(\mu \mathrm{m})$ from the start of each $\mathrm{Sr}$ label to the peak concentration (ppm) within a Sr label line is given for each Sr line (Pre-peak in Table 1 and 'a' in Fig 7 inset). The distance from the peak Sr value $(\mu \mathrm{m})$ to the end of the label (Post-peak in Table 1 and ' $b$ ' in Fig 7 inset) where baseline levels return is given for each $\mathrm{Sr}$ line (1-6). On average, the distance from the start of the Sr line in enamel to the peak value was $100 \mu \mathrm{m}$ and $31 \mu \mathrm{m}$ in dentine (Table 1). The rate of enamel formation close to the EDJ in this region was previously estimated to be $\sim 4.0 \mu \mathrm{m} /$ day (SD 0.26 ) and the rate of dentine formation $\sim 1 \mu \mathrm{m} /$ day (SD 0.1). The average period of enamel overprinting for all six Sr label lines combined was therefore 100/4=25 days (range 12.5 to 35 days). In dentine this was $31 / 1=31$ days (range 25 to 45 days). The mean estimated time for Sr levels to return to baseline/background levels in enamel was less than this, 16.3 days (range 10 to 24 days). However, in dentine the mean time was 26 days (20 to 30 days). The rise and fall in $\mathrm{Sr}$ concentration either side of each peak value was near-symmetrical but with a suggestion that the post-peak Sr clearance times in enamel were slightly faster than in dentine (Table 1). It should be noted that if rates of enamel or dentine formation were greater than $4 \mu \mathrm{m} /$ day and $1 \mu \mathrm{m} /$ day respectively, as they are likely to be in outer enamel and in deeper dentine, then these estimates for overprinting and clearance times would be shorter. Dentine rates of $1.56 \mu \mathrm{m} /$ day between lines 4 and 5, for example, would reduce the estimate of overprinting to 29 days and clearance time to 13 days. The Sr line labels each differ in thickness and intensity and the total time involved in their formation can be estimated to be between 24 and 46 days in enamel and 50 and 65 days in dentine depending on the rates of formation (Table 1). The range of values for peak $\mathrm{Sr}$ concentration varied between 334 and 1,068 ppm. There appears to be no clear relationship between peak $\mathrm{Sr}$ concentration and the total period of Sr incorporation into enamel or dentine, although larger peaks may take slightly longer to clear to base-level.

\section{Discussion}

Both the male and female orangutan canine teeth used in this study were from old individuals as evidenced by occlusal wear, chronic periodontal disease and the amount of secondary dentine and cementum laid down (Figures 1, 2 \& 4). What is surprising is their total length of tooth formation time. The enamel formation time cannot be known, given the wear and damage to each ground section, although 
these are known to be long in orangutans (Schwartz \& Dean, 2001; Smith, 2016). Canine formation times, in excess of 15 and 22 years for the female and male canines respectively, exceed the total tooth formation time previously reported for any tooth type in great apes. Kralick et al. (2017) reported a gorilla with a completed M3 root apex sometime prior to 14.94 years of age but no published data exist for completion of the canine root apex among known age great apes. However, given that both male and female orangutan canine roots are longer than their unworn crowns, that can take 9.64 years (males) and 6.27 years (females) to complete (Schwartz et al. 2001), it is perhaps not surprising that total canine completion times might on occasions be more than double this time. Of note in this respect is canine root apex completion in a wild-shot male chimpanzee (G67.2 in the collection of the Royal College of Surgeons of England) that was estimated to have occurred at 18.27 years using the same histological methods described here (unpublished data) but which was an outlier in a sample of 13 chimpanzee canines where the mean age at apex closure of the other 12 specimens was 11.15 years (range 9.46-13.38; SD 1.49). The longitudinal record of trace element incorporation into enamel and dentine that this extended tooth formation time provides, effectively through the whole of growth and development of the individual and well into adulthood, offers invaluable insight into how once free-living primate material can be made use of today.

Potentially, each tooth contains a record of diet, seasonality, climate and/or stress for a 15-22-year period $\sim 100$ years ago, depending on which trace elements and stable isotopes remain detectable in the enamel and/or dentine.

\subsection{The source of ingested strontium}

Both orangutan canines studied here show a general diffuse background level of $\mathrm{Sr}$ that alternates through periods of relative enrichment and depletion. Superimposed upon this are seemingly random short, sharp and intense Sr labels that span the whole period of tooth formation. While the source of $\mathrm{Sr}$ is unknown, it seems clear it would have been ingested. Less than $10 \%$ of ingested $\mathrm{Sr}$ is absorbed by the gastrointestinal tract but $90 \%$ of that is found in bones and teeth (Ezzo, 1994). Orangutan diet is extremely diverse and includes 453 genera of plants (leaves, fruits, seeds, flowers, pith and bark), invertebrates (termites, caterpillars, leeches, bee larvae, wasps, maggots, crickets, ticks), occasional meat (tree rats, slow loris and gibbons) as well as honey, fungi and eggs (Russon et al. 2009). Orangutan diet also varies greatly with habitat type (swamp, hill, lowland) and quality (secondary, logged, pristine), with seasonality and with mast-fruiting (the synchronous fruiting of many tree genera) as well as with other irregular supra-annual periods of severe food scarcity (Russon et al. 2009; Harrison et al. 2010). At times when fruit is scarce, orangutans may fall back to eating bark, cambium, buds and foliage (Russon et al. 2009; Mahaney, 2016). Many plants, but not all, contain Sr in their roots or shoots at a greater concentration than in soil, and concentrations have been reported to range between 49.7 to 483.7 ppm worldwide (Bowen \& Dymond, 1955; Sasmaz \& Sasmaz, 2017).

Orangutans have been observed to eat Mezzettia parviflora seeds at a number of locations in Borneo and Sumatra and nuts in particular are known to be a food source with high Ba and Sr content (Furr et al. 1979; Parek, Khan, Torres \& Kitto, 2008). At Sabangau, central Kalimantan, adult orangutans were observed to spend 13.3 to $18.2 \%$ of their total monthly feeding time consuming these seeds (Lucas et 
al. 2011). However, this comparatively large proportion of time spent on a regular basis would not explain the irregularity of the time intervals between the more intense Sr lines in dentine and enamel.

Nutritional and environmental stress, which may then place compensatory mineral demands on skeletal stores, are known to raise serum corticosterone levels (Henneicke et al. 2017; Suarez-Bregua, Guerreiro \& Rotlant, 2018). These are even transferred to infants through breastmilk (Hinde et al. 2015). Stress induced bone loss appears to be mediated via enhanced glucocorticoid signalling within osteoblasts and osteocytes, which then subsequently triggers increased osteoclast activity and bone resorption. However, in mice at least, this stress response that results primarily in vertebral and long bone trabecular bone loss, only occurs in male mice, female mice apparently being resistant to these particular effects of stress. Moreover, while initial bone loss may be rapid, prolonged stress leads to a profound reduction in bone turnover (Henneicke et al. 2017). Dirks, Humphrey, Dean \& Jeffries (2010) have also linked accentuated stress lines in juvenile baboon teeth characterised by shifts in normalised $\mathrm{Sr}$ intensities ( $\mathrm{Sr} / \mathrm{Ca}$ ) to weaning stress during early dietary transitions. Similarly, Austin et al. (2016) have linked elemental signatures in teeth, including $\mathrm{Sr}$, to known stress events in captive macaques. Under controlled environmental conditions acute bands of high Sr concentration were thought to result from bone resorption and the resulting raised plasma Sr level. The ultimate source of the $\mathrm{Sr}$ enriched bone is, however, unclear but the nature of the $\mathrm{Sr}$ stress bands in teeth clearly differed from more diffuse $\mathrm{Sr}$ bands that result from gradual changes in diet (Austin et al. 2016). Unquestionably, Sr released from the skeleton during periods of stress would contribute to circulating plasma Sr levels and to any overall fluctuations in relative Sr enrichment and depletion. However, it is hard to see how repeated Sr labels in enamel and dentine, laid down over 15 to 22 years of skeletal turnover, many with concentrations several times background levels, could all be repeatedly drawn from skeletal reserves with no other source of ingested $\mathrm{Sr}$. In this study none of the Sr lines visible in dentine or enamel are associated with accentuated incremental markings of the kind usually associated with stress events when the ground sections are view in TLM. Regular striae in enamel remain equally spaced but some appear as brighter bands where Sr lines superimpose over their whole width (Fig. 10). The last formed Sr line illustrated in Figure 6 occurs close to an enamel surface defect (although this may be a pit and not a linear hypoplastic defect) but it crops out at the enamel surface as ameloblasts are recovering and not at the start of the defect.

Kohn, Morris \& Olin (2013) have expressed caution about the origins of trace elements in free-living terrestrial carnivores and herbivores that can easily be compromised by unknown rates and quantities of dust and soil ingestion on food rather than only having a dietary origin. Seasonal events such as the annual dusty Harmattan winds in sub-Saharan Africa or hot dusty dry seasons elsewhere (Stoorvogel, Van Breemen, \& Jassen, 1997; Ogunseitan, 2007; Okeahialam, 2016; Stuhlträger, Schulz-Kornas, Wittig, \& Kupczik, 2019) are one likely source of trace element inhalation and ingestion, although a less likely source in a rain forest environment. Besides this, orangutans also consume clay soils some of which are rich in kaolinite and this has been reported to be an occasional or even a routine behaviour (Russon et al. 2009; Mahaney, 2016). Geophagy is the deliberate ingestion of soil or earth not associated with eating insects or other food. Geophagy 
is widespread across the animal kingdom particularly among herbivores and omnivores (Kruelen \& Jager 1984) but also among primates (Krishnamani \& Mahaney 2000; Pebsworth, Huffman, Lambert \& Young, 2019). Soils absorb toxins such as tannins and have an antacid and an anti-diarrhoeal action as well as being a potential source of minerals (Krishnamani \& Mahaney, 2000). Mahaney et al. (2016) analysed the elemental composition of soils consumed by orangutans in Sungai Wain Forest Preserve (Wanariset), Borneo, and reported high levels of Al, Fe and K, but these elements are not readily incorporated into mineralising teeth and bones. Levels of Sr were 49 28 ppm in consumed samples, and Hatîpoglu et al. (1990) have reported that $\mathrm{Sr}$ absorption is favoured in kaolinite and montmorillonite clays. Calcium levels were, however, below detection limits in these samples although $\mathrm{Ba}$ levels in consumed samples were $196 \mathrm{ppm}( \pm 64)$. Since fluoride when ingested at concentrations of 2 to 4 ppm manifests in enamel at between 200 to 600 ppm (Yoon, Brudevold, Gardner \& Smith, 1960; Whitford, 1997), it follows Sr ingested at 49 \pm 28 ppm (depending on the quantity ingested and degree of biopurification) might easily result in enamel concentration peaks of 700 to 1,600 ppm (Figure 6).

The best speculative guess about the source of $\mathrm{Sr}$ in these two orangutan canines is that it reflects a general background intake from ground water, multiple dietary sources, from dust and soil on food and from skeletal reserves during stress events that may each fluctuate for any number of reasons. However, cyclical breastmilk ingestion and weaning stress over such a long period of time (even continuing on through secondary dentine formation) can be confidently excluded in these two orangutans (Smith et al. 2017; Joannes-Boyau et al. 2019). Figure 5 demonstrates that when $\mathrm{Sr}$ levels are normalised to Ca concentration $(\mathrm{Sr} / \mathrm{Ca})$ the levels in dentine are for the most part proportionate to the general degree of mineralisation. On rare occasions, when many genera of trees fruit in a synchronous manner (mast-fruiting), orangutans may feed near-continuously on a single fruit or food source. This in itself might underlie the short intense peaks in Sr concentration that occur apparently randomly throughout tooth formation but on the other hand as many as 5 or 6 such events within a year (Figure 6) would seem unlikely. An alternative explanation is that orangutans experience bouts of gastrointestinal upset, perhaps especially when eating quantities of unripe (and acidic) fruits (Lucas, 1989) or during mast-fruiting events, or simply when under-nourished and/or ill and stressed. Orangutans spend prolonged bouts of time (35.2\% to $42.9 \%$ of months) in negative energy balance as judged by ketones detected in the urine (Harrison et al. 2010) and this may render them more susceptible to illness. As has been observed in free-living chimpanzees that eat termite mound soil at times when they were suffering from severe diarrhoea (Mahaney et al. 1997), so too orangutans may resort to more intense bouts of geophagy during such times. The level of Sr recorded in clay soils is certainly sufficient to incorporate into forming enamel and dentine (and bone), especially if sufficient quantities were ingested during repeated bouts of geophagy. Intriguing and important as the source of $\mathrm{Sr}$ in these orangutan canines is, it does not influence or affect the observations made about its distribution and incorporation into enamel and dentine.

The baseline, or background levels of $\mathrm{Sr}$ measured in these orangutan canines are higher in the female in both enamel and dentine, even when $\mathrm{Sr}$ is normalised for $\mathrm{Ca}$ (Figure 5). Minimum values recorded in the female canine dentine (mean, 224 ppm; range 215 to $251 \mathrm{ppm}$ ) exceed those in the male (mean,168 ppm; range 145 to 182 
ppm). For comparison, Shepherd et al. (2012) reported much lower $\mathrm{Sr}$

concentrations in the deciduous dentine of 3 children of UK origin to be $38 \pm 3 \mathrm{ppm}$, $65 \pm 8 \mathrm{ppm}$ and $135 \pm 13 \mathrm{ppm}$ respectively, the differences between them being attributable to diet and nursing history. Dean, Spiers, Garrevoet \& Le Cabec (2019b) also reported $\mathrm{Sr}$ concentrations in deciduous enamel and dentine that ranged between 100 and $150 \mathrm{ppm}$. Sex differences in gastrointestinal Sr absorption have been reported in rats and monkeys but not in great apes and humans (Dahl, et al. 2001). More likely, different local habitats and/or dietary preferences underlie these differences but the generally higher levels in dentine than are reported for modern humans would be expected given such a high plant-based diet in orangutans (Ezzo, 1994). As well as $\mathrm{Sr}$ absorbed from the gastrointestinal tract, whatever the source might be, $\mathrm{Sr}$ is constantly being released from bone as part of normal $\mathrm{Ca}$ homeostasis and bone turnover. Exactly what the residence time might be for skeletal Sr retention in orangutans is unknown but Antonini \& Luder (2011) have demonstrated that minocycline labels incorporated into mineralising alveolar bone surfaces can remain there for about 2 years before being resorbed and fluoride in bone is still be present after more than 4 years (Whitford, 1997). But alveolar bone turnover is high and elsewhere in the skeleton tetracycline may persist for 9 or more years (Ibsen \& Urist, 1964). However, the data presented here for background levels in dentine (Figure 5) suggest there is no relative cumulative increase in background $\mathrm{Sr}$ levels during the period of canine tooth formation. This period of time would have encompassed the whole period of skeletal development and remodelling from an early age.

\subsection{Gradients of Sr and Zn in enamel and dentine}

The plot of $\mathrm{Sr} / \mathrm{Ca}$ (Figure 7) suggests that the generally higher Sr levels in enamel than in dentine can in part be accounted for by higher Ca concentrations. The exception appears to be in the inner enamel towards the EDJ where Sr levels are both absolutely and relatively higher than elsewhere. Previous studies have identified gradients of $\mathrm{Sr} / \mathrm{Ca}$ and $\mathrm{Zn} / \mathrm{Ca}$ in enamel (Humphrey, Jeffries \& Dean, 2004; Humphrey, Dean \& Jeffries, 2007; Humphrey, Dean, Jeffries, \& Penn, 2008a; Humphrey, Dirks, Dean, \& Jeffries, 2008b; Humphrey, Jeffries \& Dean, 2008c; Müller, Nava, Evans, Rossi, Alt \& Bondioli, 2019; Li, Nava, Reynard, Thirlwall, Bondioli \& Müller, 2020) but no comparative data exist for dentine in these studies. A comparison of $\mathrm{Sr}$ concentrations along matching enamel and dentine transects in this study shows that gradients exist in both. In dentine there is a gradual increase in $\mathrm{Sr}$ concentration away from the EDJ in the direction of tissue formation while in enamel there is a gradual decrease from the EDJ towards the enamel surface. The greater range of variation in $\mathrm{Sr}$ concentration peaks in enamel than dentine may also be because the transects defined in this study extend a greater direct distance along these gradients from the EDJ into enamel than into dentine. The gradients in both dentine and enamel are, however, greater when overall concentrations are high than when they are low suggesting perhaps, there might be greater clearance from the forming tissue front at higher concentrations.

The pattern of trace element incorporation and distribution in enamel is also known to be element-specific (Humphrey, Dean, Jeffries, \& Penn, 2008a; Müller, Nava, Evans, Rossi, Alt \& Bondioli, 2019). Figures 8-10 illustrate this and show that Zn and $\mathrm{Sr}$ are both incorporated into dentine in a manner that reflects its incremental 
formation but that the timing and distribution of peak concentrations do not superimpose precisely. This has also previously been shown to be the case in cementum (Dean, Le Cabec, Spiers, Zhang \& Garrevoet, 2018). The pattern of Sr and $\mathrm{Zn}$ distribution in enamel is completely different and surface enamel, as has previously been shown using LA-ICP-MS, is Zn rich (Humphrey, Dean, Jeffries, \& Penn, 2008a; Müller, Nava, Evans, Rossi, Alt \& Bondioli, 2019). Müller, Nava, Evans, Rossi, Alt \& Bondioli (2019) observed that $\mathrm{Zn} / \mathrm{Ca}$ ratios increased nearexponentially some 20-35 times towards outer enamel and the plots of $\mathrm{Zn}$ concentration in enamel in this study confirm this (Figures 8-10). This has been tentatively linked with the intense involvement of $\mathrm{Zn}$ in the process of enamel mineralisation and maturation (Klimuszko, Orywal, Sierpinska, Sidum \& Golebiewska, 2018; Müller, Nava, Evans, Rossi, Alt \& Bondioli, 2019). Zinc reaches highest levels in the ameloblast nucleus during enamel maturation and $\mathrm{Zn}$ is a component of alkaline phosphatase, of carbonic anhydrase, and of enzymes involved in the degradation of enamel proteins during the maturation phase such as, matrix metalloproteinase 20 (MMP-20) and enamelysin, or KLK4, (Klimuszko, Orywal, Sierpinska, Sidum \& Golebiewska, 2018). For these reasons it has been suggested $\mathrm{Zn}$ enrichment in the outer enamel might result from the retention of $\mathrm{Zn}$ originally involved in the enamel mineralisation and maturation process (Müller, Nava, Evans, Rossi, Alt \& Bondioli, 2019).

Figure 10 further demonstrates that $\mathrm{Sr}$ does not follow the same gradient or pattern of enrichment as $\mathrm{Zn}$ in outer enamel. Moreover, there is no obvious suggestion from the SXRF maps of any Sr introduction or overprinting from maturational ameloblasts. These would have been active proximal to every enriched $\mathrm{Sr}$ label over the entire enamel surface. The distribution of $Z n$ suggests it is not removed, at least not completely, by maturational ameloblasts. A decline in Sr concentration from the EDJ towards the enamel surface has previously been observed using secondary ion mass spectrometry in a series of developing human incisor tooth germs in which preeruptive enamel thickness increased at increments of 1,2, 3, 4 and 6 months of age (Sabel, Klinberg, Nietzsche, Robertson, Odelius \& Norén, 2009). This strongly suggests the declining $\mathrm{Sr}$ concentration gradient in enamel is under the tight cellular control of secretory ameloblasts as has been suggested for other components of enamel (Sasaki, Takagi \& Yanagisawa, 1997). Whether maturational ameloblasts play any further role in the exclusion or even removal of $\mathrm{Sr}$ from enamel is unknown but the results of this study suggest they do not actively introduce $\mathrm{Sr}$ at this stage.

\subsection{Strontium overprinting during enamel and dentine mineralisation}

Many previous studies have raised awareness about the potential blurring effect of the extended enamel maturation process and the potential for a consequent mismatch between the temporal record of incremental markings and the true timing of trace element and stable isotope ingestion (Sealy, Armstrong \& Schrire, 1995; Balasse, 2002; Kohn, 2002; Montgomery, Evans \& Horstwood, 2010; Montgomery, 2010). However, when a clear incremental record of enamel formation is available and has been cross-matched with trace element distributions these effects have not seemed excessive or overwhelming (Humphrey, Dean, Jeffries, \& Penn, 2008a; Smith et al. 2018; Müller, Nava, Evans, Rossi, Alt \& Bondioli, 2019). In particular, Smith et al. (2018) reported that $\delta^{18} \mathrm{O}$ and $\mathrm{Pb}$ were observed to correspond in enamel to within a few days of administration. The data presented in this study 
(Table 1) appear to align with previous studies that suggest Sr overprinting back into enamel formed before the time secretory ameloblasts were first exposed to high a $\mathrm{Sr}$ level is of the order of $\sim 25$ days (range 13 to 35 days). Furthermore, the evidence suggests that what overprinting does exist occurs during the secretory phase and is not primarily an effect of the enamel maturation process. While clearly there is a degree of imprecision in the estimates made in this study without any tight experimental controls, it may also be that different individuals with thicker or thinner enamel, and indeed representing different species, would influence this (Green et al. $2017,2018)$. Moreover, there is another inherent limitation to this study in that the data presented here are, by necessity, primarily measures of distance. Representing overprinting and clearance times in days is dependent on estimates of formation rates. Nonetheless, an unexpected finding of this study is that when corrected for rates of tissue formation the extent of overprinting appears not to differ between enamel and dentine, despite considerable differences in peak $\mathrm{Sr}$ concentrations (Table 1). The mean time estimated here for Sr overprinting in dentine was 31 days (range 25 to 45 days) but fewer label lines in dentine than in enamel could be sampled in this way. The time taken for $\mathrm{Sr}$ to return to baseline/background levels was shorter for enamel (mean 16.3 days, range 10 to 24 days) than dentine (mean 26 days, range 20 to 30 days) but again sample sizes are too small to draw firm conclusions from this. It is nonetheless important to recognise that a proportion of the $\mathrm{Sr}$ ingested that underlay each of the sudden random peaks in enamel and dentine would be incorporated into forming bone and so contribute to ongoing baseline/background levels for a very long time as skeletal $\mathrm{Sr}$ was remodelled and released.

The plots of transects across regions of high $\mathrm{Sr}$ concentration in both enamel and dentine in this female orangutan canine appear to be near-normally distributed around a peak in concentration, with the suggestion that $\mathrm{Sr}$ in enamel may return to baseline levels slightly quicker than in dentine. This is also unexpected given the very different patterns of mineralisation in enamel and dentine as well as given the great range in peak $\mathrm{Sr}$ concentration values (Table 1). Closer examination of the $\mathrm{Sr}$ SXRF dentine maps (Figures 6, 10) shows that each individual $\mathrm{Sr}$ label is in fact made up of multiple labels each with a distinct calcospheritic profile. A comparison of tetracycline labels in human enamel and dentine with the Sr labels in this study illustrates the implications of this at greater resolution (Figure 11). The individual $\mathrm{Sr}$ labels in dentine each appear to show a complex of multiple calcospheritic labels (Figures 6, 10, 11). Multiple doses of tetracyclines (or Sr) incorporated into dentine show the same interweaving calcospheritic pattern, depending on how far apart in time each dose was ingested. As a result, the mineralising front is itself very irregular even though the individual label lines are themselves finely defined. Very strongly fluorescing labels also show streaks of peritubular dentine that continues to form proximal to the mineralising front long after intertubular dentine is mineralised. These run through and beyond each label line blurring the margins (Figure 11). It is possible that any transect across such tightly spaced groups of irregular Sr labels in dentine would generate an apparently similar symmetrical rise and fall around a peak concentration values to those observed in enamel. Some caution is therefore called for in interpreting and comparing the distribution data for dentine presented in this study with enamel. If under experimental conditions it were possible to administer a series of controlled pulse-doses of $\mathrm{Sr}$ of known concentrations at regular time intervals, the distributions around a peak value in enamel and dentine might indeed 
differ. Multiple doses of Sr ingested in close succession might also explain why the distribution around each peak concentration value does not resemble a typical dose response curve where there would be a sharp rise and then a long tail off as $\mathrm{Sr}$ slowly cleared from the system. Rather, the near-symmetrical distribution around a peak value observed in this study better fits the suggestion that multiple doses were ingested and absorbed close together (as with a course of antibiotics) and that the cumulative peak concentration value was achieved some time after the first dose was ingested. If so, then the time secretory ameloblasts were first exposed to high levels of Sr would have occurred sometime prior to the concentration peak with overprinting being slightly less than $\sim 25$ days.

Austin et al. (2016) concluded that elemental banding, detected using NWR193 (New Wave Research, Inc.) laser ablation of histological sections of captive macaque teeth, was always narrower and better differentiated in dentine than enamel, attributing this to the greater lag between matrix secretion and mineralisation in enamel. However, apparently wider bands in enamel than dentine are in part the result of differences in formation rate. Boyde (1964) has demonstrated that while tetracyclines rapidly enter enamel they may then remain in the intercrystalline space before partial removal. Strontium always fluoresces more strongly in enamel than in dentine in SXRF maps (Figures 6, 10) although other fluorochrome and tetracycline labels that chelate or bind with $\mathrm{Ca}$ in dental tissues present a different picture where fluorescence in enamel is weaker than in dentine (Ibsen \& Urist, 1964; Baker, 1972; Pautke et al., 2007; Antonini \& Luder, 2011; Williamson, 2015). These observations fit the suggestion that, unlike tetracycline and fluorochromes, $\mathrm{Sr}$ is not removed from enamel by maturational (or secretory) ameloblasts, at least not to the same extent. Earlier in enamel and dentine formation, Bevelander \& Nakahara (1965) demonstrated that both ${ }^{45} \mathrm{Ca}$ and tetracycline are incorporated into enamel and dentine equally rapidly, within 1 to 3 hours, and that tetracycline binds to mineralised tissue already laid down prior to the experimental exposure period in the same pattern observed for Sr in this SXRF study of fully formed enamel and dentine. The distribution of diminished fluorescence intensity both before and after experimental exposure to tetracycline (Bevelander \& Nakahara, 1965) matches the pattern observed in this SXRF study for Sr in both enamel and dentine.

\section{Conclusions}

Two ground sections of orangutan canines, from a male and a female likely collected $\sim 100$ years ago in their natural habitat, retain an incremental record of their growth in tooth length. The total preserved tooth formation time was greater than 15 years in the female canine and 22 years in the male canine, which are both longer tooth formation times than previously reported for great apes. Superimposing the distribution of trace elements directly onto a longitudinal record of growth ensures the best possible time-resolution of changing tooth chemistry. SXRF imaging revealed a historical record of Sr incorporated into forming enamel and dentine.

SXRF imaging revealed that baseline/background levels of $\mathrm{Sr}$ in the dentine of the male canine (mean,168 ppm; range 145 to $182 \mathrm{ppm}$ ) were slightly less than background values in the female canine (mean, $224 \mathrm{ppm}$; range 215 to $251 \mathrm{ppm}$ ). However, both exceed those reported for modern human dentine (range $38 \pm 3$ ppm 
to $\sim 150 \mathrm{ppm}$ ) but fit with the predominantly plant-based diet of orangutans. There was no relative cumulative increase in background Sr levels over the period of canine tooth formation which remained proportionate to $\mathrm{Ca}$ concentration.

Both male and female orangutan canines contained apparently random short, intense $\mathrm{Sr}$ labels superimposed onto the more diffuse fluctuating background $\mathrm{Sr}$ levels. The peak values in dentine ranged from 430 to $660 \mathrm{ppm}$ above an adjacent baseline value of $\sim 300 \mathrm{ppm}$. In enamel, peak values ranged between 630 to 1,625 ppm above adjacent baseline values (450-750 ppm). The greatest peak $\mathrm{Sr}$ concentration reached in dentine was $660 \mathrm{ppm}$ and in enamel was $\sim 1,625 \mathrm{ppm}$. The source of the Sr underlying these peaks is unknown but might relate to short episodes of mast-feeding on specific foodstuffs, to bouts of geophagy or to stress events.

A comparison of Sr concentrations in the female orangutan canine crown, made with greater resolution SXRF imaging across matching enamel and dentine label lines, showed that gradients exist in both. In dentine there was a gradual increase in $\mathrm{Sr}$ concentration away from the EDJ towards the pulp while in enamel there was a gradual decrease away from the EDJ towards the enamel surface. SXRF plots of 6 intense Sr labels through time showed a symmetrical rise and fall around a peak value in both enamel and dentine that was independent of peak Sr concentration. This distribution extended $\sim 25$ days either side of the peak in $\mathrm{Sr}$ concentration. If peak values approximate the time of Sr ingestion, then Sr overprinted back into both enamel and dentine formed prior to this time by $\sim 25$ days and continued to appear in enamel and dentine forming after this time for a further $\sim 25$ days. Besides this, $\mathrm{Sr}$ ingested at this time but laid down in bone would likely contribute to background levels for a long time through ongoing bone remodelling. The pattern of $\mathrm{Zn}$ distribution in this same region of interest in the female orangutan section was used to further compare the pattern of enamel and dentine mineralisation and in particular to explore the potential effects of enamel maturation on $\mathrm{Sr}$ and $\mathrm{Zn}$ distribution.

Maturational ameloblasts actively transport $\mathrm{Ca}$ and other ions into enamel long after secretory ameloblasts have ceased to do so. Consistent with this, SXRF images of the female orangutan section show a pattern of $\mathrm{Zn}$ distribution with diffuse but increasing enrichment (1,500 to $2,000 \mathrm{ppm})$ towards the enamel surface. The pattern of Sr distribution, however, contrasts with that for $\mathrm{Zn}$ and shows no evidence of a diffuse distribution towards the enamel surface or anywhere else. Indeed, outer and surface enamel is relatively depleted in Sr. While there is a constant baseline/background level of $\mathrm{Sr}$ in both enamel and dentine, likely derived from the diet and/or from ongoing skeletal remodelling, short intense Sr labels follow the primary incremental pattern of enamel and dentine formation. This is not the case for $\mathrm{Zn}$ in enamel (Figure 10). There is then no evidence from this study to suggest the enamel maturation process overprints or overwhelms Sr previously laid down by secretory ameloblasts to any measurable degree.

\section{Conflict of interest}

The authors declare no conflict of interest. All authors have read and approved the final article. 


\section{Ethics statement}

All work carried was exempt from any ethics requirements

\section{Acknowledgements}

All preparatory lab work was carried out at UCL and on collections based there. All experimental work was carried out at Deutsches Elektronen-Synchrotron (DESY), Hamburg, a member of the Helmholtz Association HGF, on the PETRA III P06 beamline and supported in part through Maxwell computational resources operated at DESY, Hamburg, Germany. The work presented in this study was supported by DESY Project proposals I-20160686, I-20180047 and I-20190203 and by the project CALIPSOplus under the Grant Agreement 730872 from the EU Framework Programme for Research and Innovation HORIZON 2020. We thank the DESY User Office, Drs. Gerald Falkenberg and Kathryn Spiers and those who have developed techniques employed in this study, and Mrs Anastasia Brozou, PI for beamtime Proposal I-20190203. We are grateful to Tim Bromage, Benjamin Fuller, Kornelius Kupczik and Marcello Mannino for discussions. SJM is a post-doc of the Flemish Research Foundation (grant 12S5718N). We acknowledge support to CD from the Calleva Foundation and to ALC from The Max Planck Society. We thank JeanJacques Hublin for continuing support with this project and we extend our sincere thanks to the referees for their helpful comments and suggestions.

\section{References}

Al-Mosawi, M., Davis, G. R., Bushby, A., Montgomery, J., Beaumont, J. \& Al-Jawad, M. (2018). Crystallographic texture and mineral concentration quantification of developing and mature human incisal enamel. Scientific Reports, 8, 14449 https://doi:10.1038/s41598-018-32425-y

Antonini, L.G. \& Luder, H.U. (2011). Discoloration of teeth from tetracyclines - even today? Schweiz Monatsschr Zahnmed, 121, 414-422.

Austin, C., Smith, T.M., Farahani, R.M.Z., Hinde, K., Carter, E.A., Lee, J., Lay, P.A., Kennedy, B.J., Sarrafpour, B., Wright, R.J., Wright, R.O. \& Arora, M. (2016). Uncovering system-specific stress signatures in primate teeth with multimodal imaging. Scientific Reports, 6:18802. Doi: 10:1038/srep18802.

Baker, K.L. (1972). The fluorescent, microradiographic, microhardness and specific gravity properties of tetracycline-affected human enamel and dentine. Archives of Oral Biology, 17, 525-536.

Balasse, M. (2002). Reconstructing dietary and environmental history from enamel isotopic analysis: Time resolution of intra-tooth sequential sampling. International Journal of Osteoarchaeology, 12(3), 155-65.

Balasse, M., Ambrose S.H., Smith A.B. \& Price T.D. (2002). The seasonal mobility model for prehistoric herders in the south-western cape of South Africa assessed by isotopic analysis of sheep tooth enamel. Journal of Archaeological Science, 29, 917932. 
Balasse, M., Smith A.B., Ambrose S.H. \& Leigh S.R. (2003). Determining sheep birth seasonality by analysis of tooth enamel oxygen isotope ratios: The Late Stone Age site of Kasteelberg (South Africa). Journal of Archaeological Science, 30, 205-215.

Bawden, J.W. (1989). Calcium transport during mineralization. The Anatomical Record, 224, 226-233.

Beaumont, J. (2020). The whole tooth and nothing but the tooth: or why temporal resolution of bone collagen may be unreliable. Archaeometry 62, 626-645.

Beaumont, J., Gledhill, A., Lee-Thorp, J., Montgomery, J., (2013). Childhood diet: A closer examination of the evidence from dental tissues using stable isotope analysis of incremental human dentine. Archaeometry, 55, 277-295.

Beaumont, J., Gledhill, A. \& Montgomery, J. (2014). Isotope analysis of incremental human dentine: towards higher temporal resolution. Bulletin of International Association of Paleodontology, 8(2), 212-223.

Beaumont, J., Montgomery, J., Buckberry, J., Jay, M., (2015). Infant mortality and isotopic complexity: New approaches to stress maternal health, and weaning. American Journal of Physical Anthropology, 157, 441-457.

Bentley, R.A. (2006). Strontium isotopes from the earth to the archaeological skeleton: a review. Journal of Archaeological Method and Theory 13(3), 135-187.

Bevelander, G. \& Nakahara, H. (1965). Correlation between tetracycline binding and mineralization in dentine and enamel. Anatomical Record, 153, 141-148.

Boesenberg, U., Ryan, C. G., Kirkham, R., Siddons, D. P., Alfeld, M., Garrevoet, J., Nunez, T., Claussen, T., Kracht, T., \& Falkenberg, G. (2016). Fast X-ray microfluorescence imaging with submicrometer-resolution integrating a Maia detector at beamline P06 at PETRA III. Journal of Synchrotron Radiation, 23(6), 1550-1560. https://doi.org/10.1107/S1600577516015289

Bowen, H.J.M. \& Dymond, J.A. (1955). Strontium and barium in plants and soils. Proceeding of The Royal Society London B, 144 (issue 916), 355-368 doi:10.1098/rspb.1955.0063

Bourgon, N., Jaouen, K., Bacon, A-M., Jochum, K.P., Dufour, E., Duringer, P., Ponche, J-L., Joannes-Boyau, R., Boesch, Q., Antoine, P-O., Hullot, M., Weis, U., Schulz-Kornas, E., Trost, M., Fiorillo, D., Demeter, F., Patole-Edoumba, E., Shackelford, L. L., Dunn, T. E., Zachwieja, A., Duangthongchit, S., Sayavonkhamdy, T., Sichanthongtip, P., Sihanam, D., Souksavatdy, V., Hublin, J-J. \& Tütken, T. (2020). Zinc isotopes in Late Pleistocene fossil teeth from a Southeast Asian cave setting preserve paleodietary information. Proceedings of the National Academy of Sciences 117 (9), 4675-4681; doi: 10.1073/pnas.1911744117

Boyde, A. (1964). The structure and development of mammalian enamel. PhD Thesis, London: University of London 
Boyde, A. (1989). Enamel. In A. Oksche \& L. Vollrath (Eds.). Handbook of microscopic anatomy, Vol. 2, Teeth. (pp. 309-473). Berlin: Springer Verlag.

Boyde, A. (1997). Microstructure of enamel. In: Chadwick, D. J., Cardew, G. (Eds.). Dental enamel. Proceedings of the Ciba Foundation Symposium 205. (pp. 18-31), Chichester, John Wiley and Sons Inc.

Bradford, E.W. (1958). The maturation of dentine. British Dental Journal 105, $122-$ 216.

Crabb, H.S.M. (1959). The pattern of mineralization of human dental enamel. Proceedings of the Royal Society of Medicine, 52, 118-122.

Czermak, A., Fernández-Crespo, T., Ditchfield, P. W. \& Lee-Thorp, J. A. (2020). A guide for anatomically sensitive dentine microsampling and age-alignment approach for human teeth isotopic sequences. American Journal of Physical Anthropology 2020;e24126. https://doi.org/10.1002/ajpa.24126

Dahl, S.G., Allain, P., Marie, P.J., Mauras, Y., Boivin, G., Ammann, P., Tsouderos, Y., Delmas, P.D. \& Christiansen, C. (2001). Incorporation and distribution of strontium in bone. Bone, 28, 446-453.

Dean, M.C. (2010). Retrieving chronological age from dental remains of early fossil hominins to reconstruct human growth in the past. Philosophical Transactions of The Royal Society, London, Series B ,365(1556), 3397-3410.

Dean, M.C. (2012a). A histological method that can be used to estimate the time taken to form the crown of a permanent tooth. In, (L.S. Bell, ed) Forensic microscopy for skeletal tissues, Methods and Protocols. Methods in Molecular Biology. 915: 89-100. Humana Press (Springer Science, Business-Media LLC), New York. ISBN 978-1-61779-976-1.

Dean, M.C. (2012b). Daily rates of dentine formation and root extension rates in Paranthropus boisei, KNM-ER 1817, from Koobi Fora, Kenya. In, African Genesis. Perspectives on Hominin Evolution. Editors: S. C. Reynolds, A. Gallagher, pp. 268279. Cambridge University Press, Cambridge.

Dean, M.C., Jones, M.E. \& Pilley, J.R. (1992). The natural history of tooth wear, continuous eruption and periodontal disease in wild shot great apes. Journal of Human Evolution, 22, 23-39.

Dean, M.C. \& Cole, T.J. (2013). Human life history evolution explains dissociation between the timing of tooth eruption and peak rates of root growth. PLOS ONE 8(1); 1-14, e54534. doi: 10.1371/journal.pone.0054534

Dean, C., Le Cabec, A., Spiers, K., Zhang, Y, \& Garrevoet, J. (2018). Incremental distribution of strontium and zinc in great ape and fossil hominin cementum using synchrotron X-ray fluorescence mapping. Journal of The Royal Society Interface, 15, 20170626 http://dx.doi.org/10.1098/rsif.2017.0626 
Dean, M.C., Garrevoet, J., Spiers, K.M., Rak, Y., Lahr, M., Foley, R., and Le Cabec, A. (2019a). The distribution of zinc in modern and fossil enamel, dentine and cementum. Proceedings of the European Society for the Study of Human Evolution 8; 46, 19-21st September 2019, Liège, Belgium.

https://www.eshe.eu/static/eshe/files/PESHE/PESHE 2019 OnlinePESHE.pdf

Dean, M.C., Spiers, K.M., Garrevoet, J., \& Le Cabec, A. (2019b). Synchrotron X-ray fluorescence mapping of $\mathrm{Ca}, \mathrm{Sr}$ and $\mathrm{Zn}$ at the neonatal line in human deciduous teeth reflects changing perinatal physiology. Archives of Oral Biology, 104, 90-102. doi:10.1016/j.archoralbio.2019.05.024

Dean, M.C., Humphrey, L., Groom, A. \& Hassett, B. (2020). Variation in the timing of enamel formation in modern human deciduous canines. Archives of Oral Biology, 114, 2020.104719 doi:10.1016/j.archoralbio.

Dirks, W., Humphrey, L.T., Dean, M.C. \& Jeffries, T.E. (2010). The relationship of accentuated lines in enamel to weaning stress in juvenile baboons (Papio hamadryas anubis). Folia Primatologica, 81, 207-223

Ezzo, J.A. (1994). Putting the "chemistry" back into archaeological bone chemistry analysis: Modeling potential paleodietary indicators. Journal of Anthropological Archaeology, 13,1-34.

Fahy, G.E., Richards, M.P., Fuller, B.T., Deschner, T., Hublin, J-J., \& Boesch, C. (2014). Stable nitrogen isotope analysis of dentine serial sections elucidate sex differences in weaning patterns of wild chimpanzees (Pan troglodytes). American Journal of Physical Anthropology, 153(4), 635-642.

Falkenberg, G., Fleissner, G., Fleissner, G., Alraun, P., Boesenberg, U., \& Spiers, K. (2017). Large-scale high-resolution micro-XRF analysis of histological structures in the skin of the pigeon beak. X-Ray Spectrometry, 46(5), 467473. https://doi.org/10.1002/xrs.2769

Forien, J-P., Fleck, C., Cloetens, P., Duda, G., Fratzl, P., Zolotoyabko, E. \& Zaslansky, P. (2015). Compressive residual strains in mineral nanoparticles as a possible origin of enhanced crack resistance in human tooth dentine. Nano Letters, $15,3729-3734$.

Fuller, B.T., Richards, M.P. \& Mays, S.A. (2003). Stable carbon and nitrogen isotope variations in tooth dentine serial sections from Wharram Percy. Journal of Archaeological Science, 30(12), 1673-1684.

Furr, K.A., MacDaniels L.H., St. John, L.E., Gutenmann, W.H., Pakka, I.S. \& Lisk, D.J. (1979). Elemental composition of tree nuts. Bulletin of Environmental Contamination and Toxicology, 21, 392-396.

Granstrom, G. \& Linde, A. (1981). ATP-dependent uptake of $\mathrm{Ca}^{++}$by a microsomal fraction from rat incisor odontoblasts. Calcified Tissue International, 33, 125-128. 
Green, D.R., Green, G.M., Colman, A.S., Bidlack, F.B., Tafforeau, P. \& Smith, T.M. (2017). Synchrotron imaging and Markov Chain Monte Carlo reveal tooth mineralization patterns. PLOS ONE 12(10): e0186391.

Green, D.R., Smith, T.M., Green, G.M., Bidlack, F.B., Tafforeau, P \& Colman, A.S. (2018). Quantitative reconstruction of seasonality from stable isotopes in teeth. Geochimica et Cosmochimica Acta 235, 483-504

Guatelli Steinberg, D., Floyd. B.A., Dean, M.C. \& Reid, D.J. (2012). Enamel extension rate patterns in modern human teeth: two approaches designed to establish an integrated context for fossil primates. Journal of Human Evolution 63, 475-486.

Hammarström, L. (1967). Different localization of tetracycline and simultaneously injected radiocalcium in developing enamel. Calcified Tissue Research, 1, 229-242.

Harrison, M.E., Morrogh-Bernard, H.C. \& Chivers, D.J. (2010). Orangutan energetics and the influence of fruit availability in the nonmasting peat-swamp forest of Sabangau, Indonesian Borneo. International Journal of Primatology, 31, 585-607. (doi:10.1007/s10764-010-9415-5)

Hatîpoglu, S., Eylem, C., Göktürk, H. \& Erten, H.N. et al. (1990) In, V.C. Farmer \& Y. Tardy (Eds), Proceedings of the 9th International Clay Conference, Strasbourg, 1989, Sciences Géologiques Mémoire, 86, pp. 79 - 86, Strasbourg, France.

Henneicke, H., Li, J., Kim, S., Gasparini, S.J., Seibel, M.J. \& Zhou, H. (2017). Chronic Mild Stress Causes Bone Loss via an Osteoblast-Specific GlucocorticoidDependent Mechanism. Endochronology, 158(6), 1939-1950.

Hillson, S. (2014). Tooth development in human evolution and bioarchaeology. Cambridge, UK. Cambridge University Press.

Hinde, K., Skibeil, A,L., Foster, A.B., Rosso, L.D., Mendoza, S.P. \& Capitanio, J.P. (2015). Behavioral Ecology 26(1), 269-281.

Hubbard, M. J. (2000). Calcium transport across the dental enamel epithelium. Critical Reviews in Oral Biology and Medicine, 11(4), 437-466.

Humphrey, L.T., Jeffries, T. E., Dean, M.C. (2004). Investigation of age at weaning using Sr/Ca ratios in human tooth enamel. American Journal of Physical Anthropology Supplement, 38, 117.

Humphrey L.T., Dean, M.C. \& Jeffries, T.E. (2007). An evaluation of changes in strontium/calcium ratios across the neonatal line in human deciduous teeth. In (S. E. Bailey, J-J. Hublin (Eds.). Dental Perspectives on Human Evolution: State of the Art Research in Dental Paleoanthropology (pp. 303-319). Dordrecht, Springer.

Humphrey, L.T., Dean, M.C., Jeffries, T.E. \& Penn, M. (2008a). Unlocking evidence of early diet from tooth enamel. Proceedings of The National Academy of Sciences USA, 105, 6834-9. https://doi:10.1073/pnas.0711513105. 
Humphrey, L.T., Dirks, W., Dean, M.C. \& Jeffries, T.E. (2008b). Tracking dietary transitions in weanling baboons (Papio hamadryas anubis) using strontium/calcium ratios in enamel. Folia Primatologica, 79,197-212.

https://doi:10.1159/000113457

Humphrey, L.T., Jeffries, T.E. \& Dean, M.C. (2008c). Micro spatial distributions of lead and zinc in human deciduous tooth enamel. In J.D., Irish, G.C. Nelson, (Eds.). Technique and Application in Dental Anthropology, Studies in Biological Anthropology (pp. 87-110). Cambridge University Press.

Ibsen, K. H. \& Urist, M. R. (1964). The biochemistry and the physiology of the tetracyclines: with special reference to mineralized tissues. Clinical Orthopaedics and Related Research, 32, 143-69.

Irving, J.T. (1978). Theories of mineralization in bones and teeth. In Textbook of oral biology (eds J.H. Shaw, E.A. Sweeney, C.C. Cappuccino, S.M. Meller) pp. 470-483. W.B. Saunders, Philadelphia, London, Toronto.

Joannes-Boyau, R., Adams, J.W., Austin, C., Arora, M., Moffat, I., Herries, A.I., Tonge, M.P., Benazzi, S., Evans, A.R., Kullmer, O., Wroe, S., Dosseto, A. \& Fiorenza, L. (2019). Elemental signatures of Australopithecus africanus teeth reveal seasonal dietary stress. Nature, 572, 112-115.

Kirkham, R., Dunn, P. A., Kuczewski, A. J., Siddons, D. P., Dodanwela, R. \& Moorhead, G. F. (2010). The Maia Spectroscopy Detector System: Engineering for Integrated Pulse Capture, Low-Latency Scanning and Real-Time Processing. AIP Conference Proceedings 1234, 240-3. https://doi:10.1063/1.3463181.

Klimuszko, E., Orywal, K., Sierpinska, T., Sidum, J. \& Golebiewska, M. (2018). The evaluation of zinc and copper content in tooth enamel without any pathological changes - an in vitro study. International Journal of Nanomedicine, 13, 1257-1264.

Kohn, M.J. (2004). Comment: Tooth enamel mineralization in ungulates: Implications for recovering a primary isotopic time-series, by B. H. Passey and T. E. Cerling (2002). Geochimica et Cosmochimica Acta, Vol. 68(2), 403-405

Kohn, M.J., Morris, J. \& Olin, P. (2013). Trace element concentrations in teeth - a modern Idaho baseline with implications for archaeometry, forensics, and palaeontology. Journal of Archaeological Science, 40, 1689-1699.

Kralick, A.E., Burgess, M.L., Glowacka, H., Arbenz-Smith, K., McGrath, K., Ruff, C.B., Chan, K.C., Cranfield, M.R., Stoinski, T.S., Bromage, T.G., Mudakikwa, A. \& McFarlin, S.C. (2017). A radiographic study of permanent molar development in wild Virunga mountain gorillas of known chronological age from Rwanda. American. Journal of Physical Anthropology 163, 129-147.

Kreulen, D.A. \& Jager, T. (1984). The significance of soil ingestion in the utilization of arid rangelands by large herbivores, with special reference to natural licks on the 
Kalahari pans. In: Herbivore Nutrition in the Subtropics and Tropics (Ed. by F. M. C. Gilchrist \& R. I. Mackie), pp. 204-221. Johannesburg: Science Press.

Krishnamani, R. \& Mahaney, W.C. (2000). Geophagy among primates; adaptive significance and ecological consequences. Animal Behaviour, 59, 899-915.

Leblond, C.P. \& Warshawsky, H. (1979). Dynamics of enamel formation in the rat incisor tooth. Journal of Dental Research 58, 950-975.

Li, Q., Nava, A., Reynard, L.M., Thirlwall, M., Bondioli, L. \& Müller, W. (2020). Spatially-resolved $\mathrm{Ca}$ isotopic and trance element variations in human deciduous teeth record diet and physiological change. Environmental Archaeology, doi:10.1080/14614103.2020.1758988.

Luca, P.W. (1989). Significance of Mezzettia leptopoda fruits eaten by orang-utans for dental microwear analysis. Folia Primatologica 52, 185-190.

Lucas, P.W., Gaskins, J.T., Lowrey, T.K., Harrison, M.E., Morrogh-Bernard, H.C., Cheyne, S.M. \& Begley, M.R. (2012). Evolutionary optimization of material properties of a tropical seed. Journal of The Royal Society Interface, 9, 34-42 doi:10.1098/rsif.2011.0188

Mahaney, W.C., Milner, M.W., Sanmugadas, K., Hancock, R.G.V., Aufreiter, S., Wrangham, R. \& Pier, H.W. (1997). Geophagy amongst chimpanzees in Kibale forest, Uganda, [Analysis of geophagy soils in Kibale Forest, Uganda]. Primates, 38(2), 159-176.

Mahaney, W., Hancock, R.G.V., Aufreiter, S., Milner, M.W \& Voros, J. (2016). Bornean orangutan geophagy: analysis of ingested and control soils. Environmental and Geochemical Health, 38, 51-64

Montgomery, J. (2010). Passports from the past: Investigating human dispersals using strontium isotope analysis of tooth enamel. Annals of Human Biology, 37, 325346.

Montgomery, J., Evans, J.A., \& Horstwood, M.S. (2010). Evidence for long-term averaging of strontium in bovine enamel using TIMS and LA-MC-ICP-MS strontium isotope intra-molar profiles. Environmental Archaeology, 15, 32-42.

Müller, W., Nava, A., Evans, D., Rossi, P. F., Alt, K.W., \& Bondioli, L. (2019). Enamel mineralization and compositional time-resolution in human teeth evaluated via histologically- defined LA-ICPMS profile. Geochimica et Cosmochimica Acta, 255, 105-126. https://doi.org/10.1016/j.gca.2019.03.005.

Ogunseitan, O.A. (2007). Harmattan haze and environmental health. African Journal of Environmental Science and Technology, 1(4), 1-4.

http://www.academicjournals.org/AJEST

Okeahialam, B.N. (2016). The cold dusty Harmattan: A season of anguish for cardiologists and patients. Environmental Health Insights, 10, 143-146. 
Parek, P.P., Khan, A.R., Torres, M., Kitto, M.E. (2008). Concentrations of selenium, barium and radium in Brazil nuts. Journal of Food Composition and Analysis, 21(4), 332-335.

Passey B.H. \& Cerling T.E. (2002). Tooth enamel mineralization in ungulates: Implications for recovering a primary isotopic time-series. Geochimica et Cosmochimica Acta, 66, 3225-3234.

Pautke, C., Tischer, T., Vogt, S., Haczek, C., Deppe, H., Neff, A., Horch H.-H., Schieker, M. \& Kolk, A. (2007). New advances in fluorochrome sequential labelling of teeth using seven different fluorochromes and spectral analysis. Journal of Anatomy, 210, 117-121.

Pebsworth, P.A., Huffman, M.A., Lambert, J.E. \& Young, S.L. (2019). Geophagy among nonhuman primates: A systematic review of current knowledge and suggestions for future directions. American Journal of Physical Anthropology, Supplement: Yearbook, 168, Issue S67, 164-194. https://doi.org/10.1002/ajpa.23724

Robinson, C. (2014). Enamel maturation: a brief background with implications for some enamel dysplasias. Frontiers in Physiology, Craniofacial Biology, article 388 vol 5, 1-6. https://doi:10.3389/fphys.2014.00388

Robinson, C., Kirkham, J., Brookes, S.J., Bonass, W.A. \& Shore, R.C. (1995). The chemistry of enamel development. International Journal of Developmental Biology, $39,145-152$.

Robinson, C., Brookes, S. J., Bonass, W.A., Shore, R.C., Kirkham, J. (1997). Enamel maturation. In: Chadwick, D. J., Cardew, G. (Eds.). Dental enamel. Proceedings of the Ciba Foundation Symposium 205. (pp. 118-134), Chichester, John Wiley and Sons Inc.

Rokita, E., Hermes, C., Nolting, H-F. \& Ryczek J. (1993). Substitution of calcium by strontium within selected calcium phosphates. Journal of Crystal Growth, 130, 543552.

Rosser, H., Boyde, A. \& Stewart, A.D.G. (1967). Preliminary observations of the calcium concentration in developing enamel assessed by scanning electron-probe $X$ ray emission microanalysis. Archives of Oral Biology, 12, 431-440. https://doi:10.1016/0003-9969(67)90018-0

Russon, A.E., Wich, S.A., Ancrenaz, M., Kanamori, T., Knott, C.D., Kuze, N., Morrogh-Bernard, H.C., Pratje, P., Ramlee, H., Rodman, P, Sawang, A., Sidiyasa, K., Singleton, I. \& van Schaik, C.P. (2009). Geographic variation in orangutan diet. In S. Wich, S. Utami Atmoko, T. Mitra Setia \& C. van Schaik (Eds.), Orangutans: Geographic variation in behavioral ecology and conservation. Oxford: Oxford University Press. 
Sabel, N., Klinberg, G., Nietzsche, S., Robertson, A., Odelius, H. \& Norén, J.G. (2009). Analysis of some elements in primary enamel during postnatal mineralization. Swedish Dental Journal, 33, 85-95.

Sandberg, P.A., Sponheimer, M., Lee-Thorp, J. \& Van Gerven, D. (2014). Intra-tooth stable isotope analysis of dentine: A step toward addressing selective mortality in the reconstruction of life history in the archaeological record. American Journal of Physical Anthropology, 155, 281-293.

Sasaki, T., Takagi, M. \& Yanagisawa, T. (1997). Structure and function of secretory ameloblasts in enamel formation. In: Chadwick, D. J., Cardew, G. (Eds.). Dental enamel. Proceedings of the Ciba Foundation Symposium 205. (pp. 32-50), Chichester, John Wiley and Sons Inc.

Sasmaz, M. \& Sasmaz, A. (2017). The accumulation of strontium by native plants grown on Gumuskoy mining. Journal of Geochemical Exploration, 181, 236-242.

Schroer, C. G., Boye, P., Feldkamp, J. M., Patommel, J., Samberg, D., Schropp, A., Schwab, A., Stephan, S., Falkenberg, G., Wellenreuther, G., \& Reimers, N. (2010). Hard X-ray nanoprobe at beamline P06 at PETRA III. X-Ray Mirror, 616(2), 9397. https://doi.org/10.1016/j.nima.2009.10.094

Sealy J, Armstrong R, Schrire C. (1995). Beyond lifetime averages: tracing life histories through isotopic analysis of different calcified tissues from archaeological human skeletons. Antiquity, 69, 290-300.

Schroeder, H.E. (1991). Oral structural biology. Thieme, G. Medical Publishers, Inc, New York, 424 p.

Schwartz, G.T. \& Dean, M.C. (2001). Ontogeny of canine dimorphism in extant hominoids. American Journal of Physical Anthropology, 115, 269-283.

Schwartz, G.T., Reid, D.J. \& Dean, M.C. (2001). Developmental aspects of sexual dimorphism in hominoid canines. International Journal of Primatology, 22(5), 837860.

Shepherd, T.J., Dirks, W., Manmee, C., Hodgson, S., Banks, D.A., Averley, P. \& Pless-Mulloli, T. (2012). Reconstructing the life-time lead exposure in children using dentine in deciduous teeth. Science of the Total Environment, 425, 214-222.

Simmons, L.M., Montgomery, J., Beaumont, J., Davis, G.R., Al-Jawad, M. (2013). Mapping the spatial and temporal progression of human dental enamel biomineralization using synchrotron X-ray diffraction. Archives of Oral Biology, 58, 1726-1734.

Smith, C.E. (1998). Cellular and chemical events during enamel formation. Critical Reviews in Oral Biology and Medicine, 9(2), 128-161.

Smith, T.M. (2016). Dental development in living and fossil orangutans. Journal of Human Evolution, 94, 92-105. 
Smith, T. M. \& Tafforeau, P. (2008). New visions of dental tissue research: Tooth development, chemistry and structure. Evolutionary Anthropology 17, 213-226.

Smith, T.M., Austin, C., Hinde, K, Vogel, E.R. \& Arora, M. (2017). Cyclical nursing patterns in wild orangutans. Science Advances 2017;3:e1601517.

Smith, T.M., Austin, C., Green, D.R., Joannes-Boyau, R., Bailey, S., Dumitriu, D., Fallon, S., Grün, R, James, H.F., Moncel, M-H., Williams, I.S., Wood, R. \& Arora, M. (2018). Wintertime stress, nursing, and lead exposure in Neanderthal children. Science Advances, 4(10), eaau9483. Doi: 10.1126/sciadv.aau9483

Sponheimer, M., Passey, B.H., de Ruiter, D., Guatelli-Steinberg, D., Cerling, T. \& Lee-Thorp, J. (2006). Isotopic evidence for dietary variability in the early hominin Paranthropus robustus. Science, 314, 980-982.

Sponheimer, M. \& Cerling, T. (2014). Investigating ancient diets using stable isotopes in bioapatites. Treatise on Geochemistry (Second Edition) Volume 14, 2014, Pages 341-355 https://doi.org/10.1016/B978-0-08-095975-7.01222-5

Stoorvogel, J.J., Van Breemen, N., \& Jassen, B.H. (1997). The nutrient input by Harmattan dust to a forest ecosystem in Cote d'Ivoire, Africa. Biogeochemistry, 37, 145-157. doi: 10.1023/A:1005734225727.

Stuhlträger, J., Schulz-Kornas, E., Wittig, R. M., \& Kupczik, K., (2019). Ontogenetic dietary shifts and microscopic tooth wear in western chimpanzees. Frontiers in Ecology and Evolution, 7, Article 298, 1-14. doi: 10.3389/fevo.2019.0029s

Suarez-Bregua, P., Guerreiro, P.M. \& Rotlant, J. (2018). Stress, glucocorticoids and bone: A review from mammals to fish. Frontiers in Endocrinology, 9, Article 526, doi: 103389/fendo.2018.00526.

Suga, S. (1989). Enamel hypomineralization viewed from the pattern of progressive mineralization of human and monkey developing enamel. Advances in Dental Research, 3(2), 188-198.

Tacail, T., Martin, J.E., Arnaud-Godet, F., Thackeray, F.J., Cerling, T.E., Braga, J \& Balter, V. (2019). Calcium isotopic patterns in enamel reflect different nursing behaviors among South African early hominins. Science Advances, 5(8), eaax3250. Doi: $10.1126 /$ sciadv.aax3250

Tafforeau, P., Bentaleb, I., Jaeger, J-J. \& Martin C. (2007). Nature of laminations and mineralization in rhinoceros enamel using histology and X-ray synchrotron microtomography: potential implications for palaeoenvironmental isotopic studies. Palaeogeography Palaeoclimatology and Palaeoecology, 246, 206-227.

Tsutaya, T. (2020). Blurred time resolution of dentin serial sections. American Journal of Physical Anthropology doi 10.1002/ajpa.24113 (in press). 
Weidmann, S. M., Weatherell, J. A., \& Hamm, S. M. (1967). Variations in enamel density in sections of human teeth. Archives of Oral Biology, 12, 85-97.

Williamson, R. A. (2015). Histological preparation of teeth and tooth growth. Oral Biology and Dentistry 3(3),1-6 doi: 10.7243/2053-5775-3-3

Witzel, C. (2014). Echoes from birth-Mutual benefits for physical and forensic anthropology by applying increment counts in enamel of deciduous teeth for ageing. Anthropologischer Anzeiger, 71, 87-103.

Whitford, G. M. (1997). Determinants and mechanisms of enamel fluorosis. In: Chadwick, D. J., Cardew, G. (Eds.). Dental enamel. Proceedings of the Ciba Foundation Symposium 205. (pp. 226-245), Chichester, John Wiley and Sons Inc.

Yoon, S.H., Brudevold, F., Gardner, D.E. \& Smith, F.A. (1960). Distribution of fluoride in teeth from areas with different levels of fluoride in the water supply. Journal of Dental Research 39(4), 845-856.

Zazzo, A., Balasse, M. \& Patterson, W.P. (2005). High-resolution $\delta^{13} \mathrm{C}$ intratooth profiles in bovine enamel: implications for mineralization pattern and isotopic attenuation. Geochimica et Cosmochimica Acta, 69, 3631-3642.

Zuckerman, S. (1928). Age-changes in the chimpanzee, with special reference to growth of brain eruption of teeth and estimation of age with a note on the Taung ape. Proceedings of the Zoological Society London, 1, 1-42.

Table 1

\begin{tabular}{|l|l|l|l|l|l|l|l|l|}
\hline & \multicolumn{4}{|c}{ Enamel } & \multicolumn{5}{c|}{ Dentine } \\
\hline & $\begin{array}{l}\text { Distance from each Sr peak } \\
\text { to start (Pre-peak) and end } \\
\text { (Post-peak) of label }(\boldsymbol{\mu m})\end{array}$ & $\begin{array}{l}\text { Peak highest } \\
\text { concentration } \\
(\mathbf{p p m}),(\text { SD) }\end{array}$ & $\begin{array}{l}\text { Distance from Sr peak to } \\
\text { start (Pre-peak) and end } \\
\text { (Post-peak) of label ( } \mu \mathrm{m})\end{array}$ & $\begin{array}{l}\text { Peak highest } \\
\text { concentration } \\
\text { (ppm), (SD) }\end{array}$ \\
\hline Sr Line & Pre- & Peak & Post- & & Pre- & Peak & Post- & \\
\hline 1 & 140 & 210 & 65 & $1625(24.7)$ & 25 & 120 & 30 & $437(12.5)$ \\
\hline 2 & 50 & 335 & 45 & $873(17.5)$ & - & - & - & - \\
\hline 3 & 50 & 510 & 95 & $1068(17.4)$ & 25 & 180 & 35 & $489(11.4)$ \\
\hline 4 & 140 & 775 & 95 & $733(14.6)$ & 35 & 260 & 20 & $403(10.9)$ \\
\hline 5 & 100 & 970 & 40 & $632(15.8)$ & - & - & - & - \\
\hline 5 & 105 & 135 & 70 & $1179(22.8)$ & 25 & 285 & 25 & $334(12.1)$ \\
\hline 6 & 115 & 580 & 65 & $982(18.9)$ & 45 & 475 & 20 & $651(12.4)$ \\
\hline Mean $\mu \mathrm{m}$ & 100 & & 68 & & 31 & & 26 & \\
\hline Range $\mu \mathrm{m}$ & $50-140$ & & $40-95$ & & $25-45$ & & $20-30$ & \\
\hline $\begin{array}{l}\text { Estimated } \\
\text { duration } \\
\text { (days) }\end{array}$ & $25 \pm 1.5$ & & $17 \pm 1.1$ & & $31 \pm 3.1$ & & $26 \pm 2.6$ & \\
\hline
\end{tabular}


The temporal incorporation of Sr into enamel and dentine. Each Sr line (1-6) is identified as in Figure 6 . The distance $(\mu \mathrm{m})$ of each peak (numbered 1-6) along each transect from the EDJ is given (Peak). The inset in figure 7 illustrates this position ' $p$ ' for Line 1 in enamel. Line 2 cannot be identified along the dentine transect so close to the EDJ so there are no data for this. Line 5 is crossed by both enamel transects but at different distances from the EDJ and so appears here twice. The distance $(\mu \mathrm{m})$ from the start of each Sr label to the peak concentration (ppm) within a Sr label line is given for each line 1-6 (Pre-peak). The inset in Fig. 7 illustrates this distance ' $a$ ' from peak 1. The distance $(\mu \mathrm{m})$ from the peak $\mathrm{Sr}$ value to the end of the label (Post-peak) where baseline levels return is given for each $\mathrm{Sr}$ line (1-6). The inset in Fig. 7 illustrates this distance 'b' from peak 1. Sr concentration values were generated to the nearest $5 \mu \mathrm{m}$ interval from the EDJ. The mean distance $(\mu \mathrm{m})$ and range Pre-peak to Peak and Peak to Post-peak in enamel and dentine were used to estimate duration (days). The estimated mean times for overprinting into earlier formed tissue, as well as the clearance times after the peak in concentration assume a rate of $\sim 1 \mu \mathrm{m} /$ day (SD 0.1) for dentine formation and $\sim 4 \mu \mathrm{m} /$ day (SD 0.26) for enamel formation. Greater formation rates would reduce these estimates and slower rates would increase them.

\section{Figure legends}

\section{Figure 1}

Male and female orangutans (Pongo pygmaeus) used in this study showing the upper right canine in the female (CA28_JS3, left specimen) and lower left canine in the male (CA28, right specimen) from which ground sections were made. (Photograph courtesy of Alan Boyde).

\section{Figure 2}

a) SXRF image of Sr distribution in the enamel and dentine of the upper right canine of the female Pongo (CA28_JS3) ground section. The dotted line (yellow) in the SXRF image (a) shows the dentine transect of the plot (b) for Sr concentration (ppm) against increasing tooth length $(\mu \mathrm{m})$ through coronal and then root dentine. The transect was defined in dentine first close to the EDJ then continuing along the root close to the CDJ. Alternating dark and light filled-symbols indicate successive odd and even years of tooth development. The square outline (red) indicates the position of the region of interest scanned at higher resolution (See Figs. 6, 8, 9).

\section{Figure 3}

Dentine (left image) in the upper right canine of the female orangutan (CA28_JS3) close to the cement dentine junction (CDJ) showing the granular layer of Tomes (GLT) with cementum immediately above. The arrow indicates the direction of the root apex. Daily incremental markings can be seen running obliquely in continuity from the GLT (left) to deeper formed dentine (right). The spacing between accentuated daily markings gradually increases as rates rise from $\sim 1.0$ to 2.0 $\mu \mathrm{m} /$ day in this field of view. Dentine tubules run at right angles across daily 
increments. Enamel (right image) in the upper right female orangutan canine close to the enamel dentine junction (EDJ). The arrow indicates the direction of the enamel cervix. Daily incremental markings are visible along prisms than run top to bottom in this field of view and measure $\sim 4 \mu \mathrm{m}$ apart.

\section{Figure 4}

a) SXRF image of Sr distribution in the enamel and dentine of the lower left canine of the male Pongo (CA28) ground section. The dotted line (yellow) in the SXRF image (a) shows the dentine transect of the plot (b) for Sr concentration (ppm) against tooth increasing tooth length $(\mu \mathrm{m})$ through coronal and then root dentine. The transect was defined first close to the EDJ continuing then along the root close to the CDJ.

Alternating dark and light filled-symbols indicate successive odd and even years of tooth developments. An $\sim 600 \mu \mathrm{m}$ long segment of enamel and dentine are missing in the crown as a result of previous damage to the tooth.

\section{Figure 5}

Combined male and female canine normalised $\mathrm{Sr}$ concentration $(\mathrm{Sr} / \mathrm{Ca})$ in crown and root dentine plotted together against increasing tooth length.

\section{Figure 6}

SXRF image of Sr intensity showing a series of matching Sr label lines in the enamel and dentine of the female orangutan canine ground section $(5 \mu \mathrm{m}$ resolution, $10 \mathrm{~ms}$ integration time, $0.5 \mathrm{~h}$ scan). Matching $\mathrm{Sr}$ label lines are numbered 1-6 along three transects, dentine A, enamel B and enamel C. Sr concentration (ppm) along each transect is plotted against formation time (days) from the EDJ (grey vertical line), dentine to the left, enamel to the right. Enamel transect $C$ is plotted here crossmatched with enamel transect $B$ in the correct time sequence of formation and not by distance from the EDJ.

\section{Figure 7}

$\mathrm{Sr} / \mathrm{Ca}$ in enamel is greater than in dentine towards the EDJ but reduces to the point where values for dentine and enamel superimpose as the enamel surface is approached. Enamel transect $C$ actually begins at the EDJ but is plotted here in time sequence cross-matched with dentine transect $A$ and enamel transect $B$.

\section{Figure 8}

The transects E1 and D2 are matching labels of high Sr concentration in enamel and dentine respectively in the same region of interest in the female orangutan ground section as shown in Fig. 6. Strontium concentration along transect E1 reduces away from the EDJ and towards the enamel surface. The plots for Sr concentration along transect D1 shows a gradual increase away from the EDJ. The pattern of Zn concentration is different and remains constant at a low level in dentine while rising steeply towards the enamel surface.

\section{Figure 9}


The transects E3 and D3 are matching regions of low Sr concentration in enamel and dentine respectively in the same region of interest as shown in Figs. 6 and $8 . \mathrm{Sr}$ concentration along transect E3 reduces towards the enamel surface. The plots for Sr concentration along transect D3 shows a gradual away from the EDJ. The pattern of $\mathrm{Zn}$ concentration is different and remains constant at a low level in dentine while rising steeply towards the enamel surface.

\section{Figure 10}

Transmitted light micrograph (TLM) of a wider field of view than studied previously showing more $\mathrm{Sr}$ labels in enamel and dentine but in the second ground section of the female orangutan canine (CA28-JS3). Matching SXRF images of $\mathrm{Sr}, \mathrm{Zn}$ and $\mathrm{Ca}$ were scanned on this occasion using dual Vortex EM silicon drift detectors $(5 \mu \mathrm{m}$ resolution, $10 \mathrm{~ms}$ integration time, $0.5 \mathrm{~h}$ scan). SXRF intensity scales in this figure are arbitrary units $\mathrm{(au}$ ). The pattern of $\mathrm{Zn}$ distribution in enamel is entirely different to $\mathrm{Sr}$ across the whole enamel surface where concentrations are high. However, $\mathrm{Zn}$ and $\mathrm{Sr}$ in dentine both show an incremental distribution. The Ca map shows higher concentrations in enamel than dentine but with no zone of higher concentration at the EDJ or at the enamel surface.

\section{Figure 11}

Modern human second permanent molar imaged in UV incident light showing tetracycline labels in the crown (left image) and root (middle image). Rates of dentine formation are slower than enamel and the label lines are brighter in dentine (left image). Closer examination of the label lines in dentine (middle and right images) shows they comprise multiple individual doses that each have a calcospheritic pattern. The laser confocal image (right image) shows this at higher resolution and illustrates the irregular outline of the mineralising front. The intense fluorescing line to the right represents a very high dose and streaks of peritubular dentine (see also middle image) can be seen running through the mineralising front. 


\section{Figures}

1.

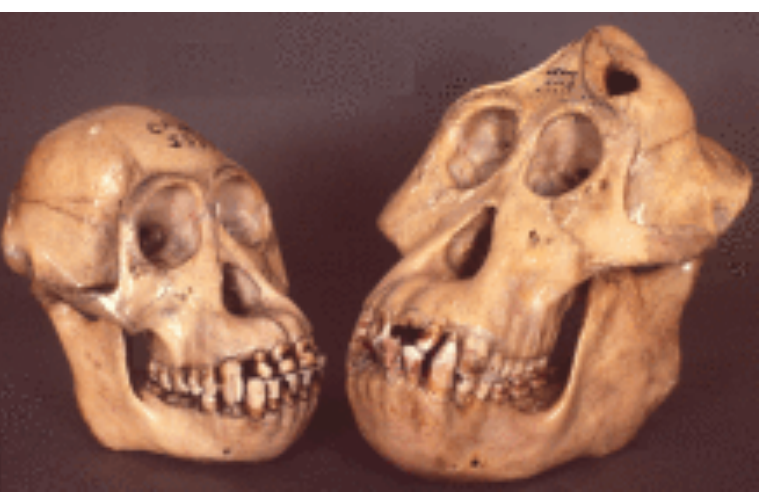

2.

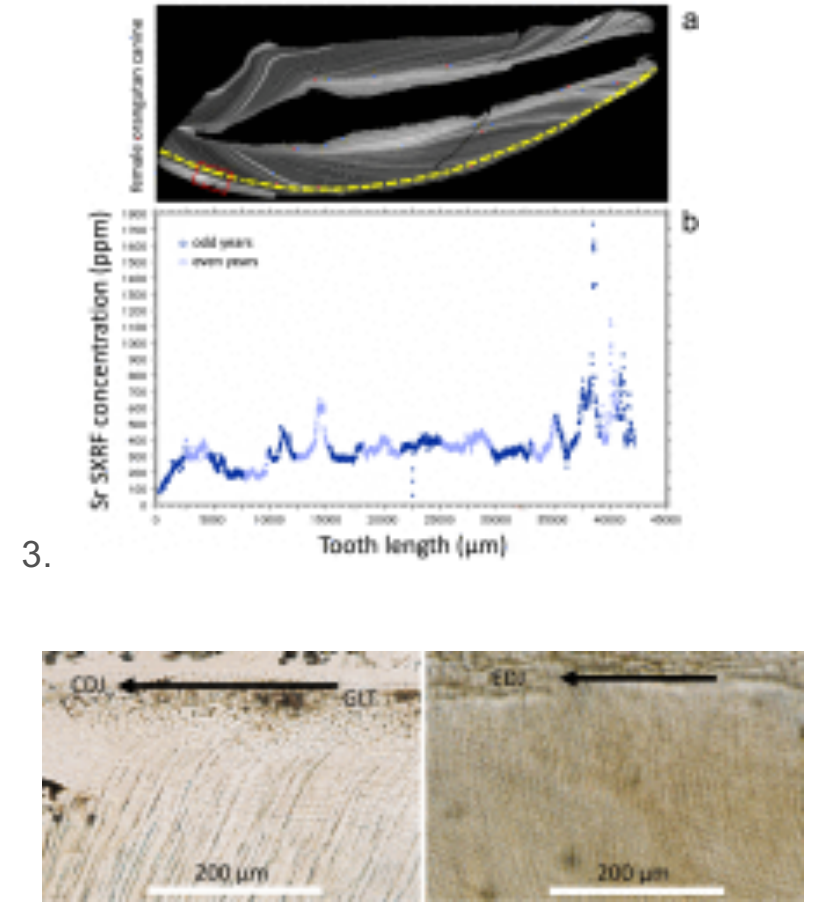

4.

5.

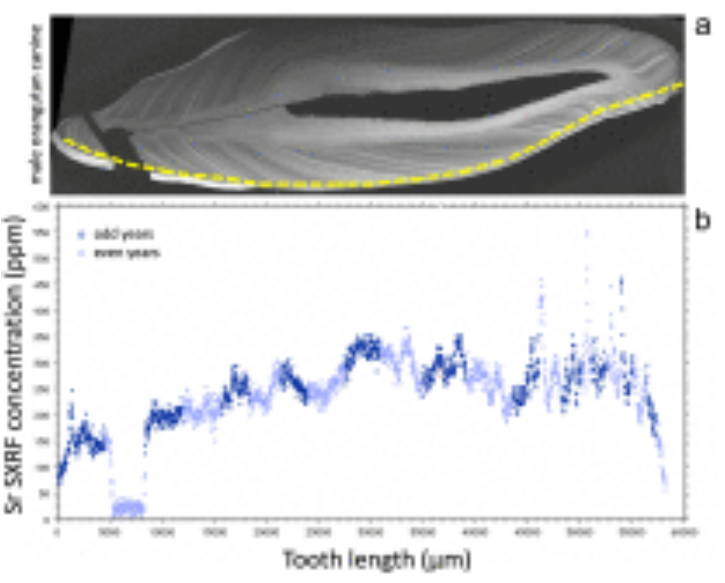


6.
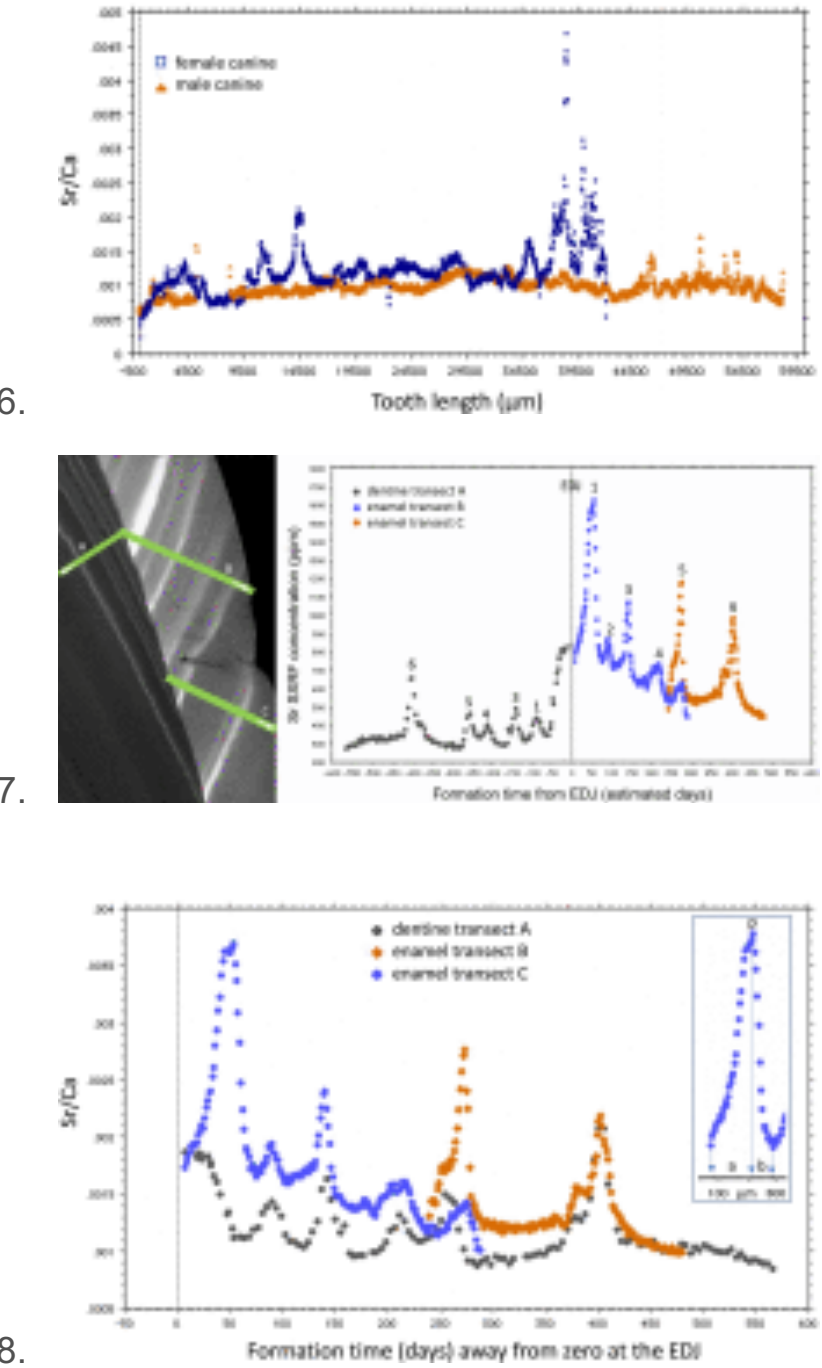

8.
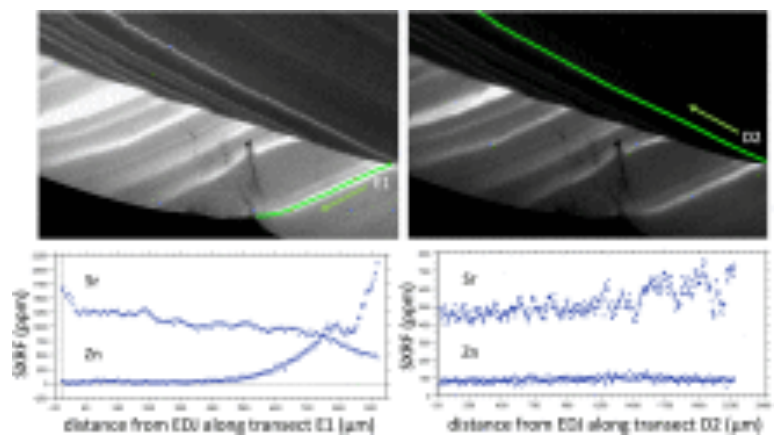

\section{9.}
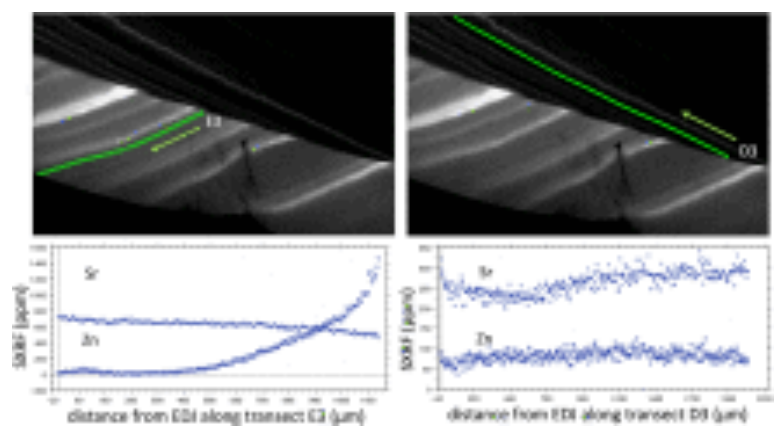

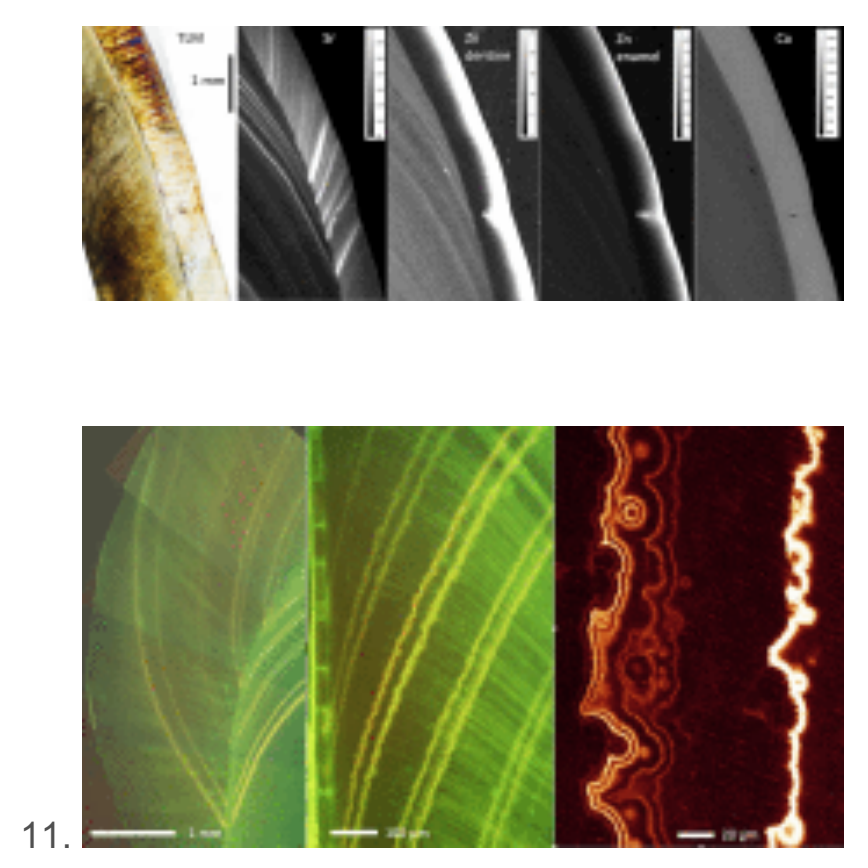